\title{
Effects of model chemistry and data biases on stratospheric ozone assimilation
}

\author{
L. Coy $^{1}$, D. R. Allen ${ }^{2}$, S. D. Eckermann ${ }^{1}$, J. P. McCormack ${ }^{1}$, I. Stajner ${ }^{3,4}$, and T. F. Hogan \\ ${ }^{1}$ Space Science Division, Naval Research Laboratory, Washington, D.C., USA \\ ${ }^{2}$ Department of Physics and Astronomy, Dordt College, Sioux Center, IA, USA \\ ${ }^{3}$ Sciences Applications International Corporation, Beltsville, MD, USA \\ ${ }^{4}$ Global Modeling and Assimilation Office, NASA Goddard Space Flight Center, Greenbelt, MD, USA \\ ${ }^{5}$ Marine Meteorology Division, Naval Research Laboratory, Monterey, CA, USA
}

Received: 16 November 2006 - Published in Atmos. Chem. Phys. Discuss.: 22 January 2007

Revised: 15 May 2007 - Accepted: 23 May 2007 - Published: 12 June 2007

\begin{abstract}
The innovations or observation minus forecast (O-F) residuals produced by a data assimilation system provide a convenient metric of evaluating global analyses. In this study, O-F statistics from the Global Ozone Assimilation Testing System (GOATS) are used to examine how ozone assimilation products and their associated O-F statistics depend on input data biases and ozone photochemistry parameterizations (OPP). All the GOATS results shown are based on a 6-h forecast and analysis cycle using observations from SBUV/2 (Solar Backscatter UltraViolet instrument-2) during September-October 2002. Results show that zonal mean ozone analyses are more independent of observation biases and drifts when using an OPP, while the mean ozone O-Fs are more sensitive to observation drifts when using an OPP. In addition, SD O-Fs (standard deviations) are reduced in the upper stratosphere when using an OPP due to a reduction of forecast model noise and to increased covariance between the forecast model and the observations. Experiments that changed the OPP reference state to match the observations by using an "adaptive" OPP scheme reduced the mean ozone O-Fs at the expense of zonal mean ozone analyses being more susceptible to data biases and drifts. Additional experiments showed that the upper boundary of the ozone DAS can affect the quality of the ozone analysis and therefore should be placed well above (at least a scale height) the region of interest.
\end{abstract}

Correspondence to: L. Coy

(coy@nrl.navy.mil)

\section{Introduction}

Ozone is a radiatively important trace gas in the middle atmosphere. As global numerical weather prediction (NWP) models extend upward and become more reliant on satellite observations, accurate modeling of the radiative environment, including ozone, seen by these models becomes more important for optimal use of satellite radiances (e.g., Derber and $\mathrm{Wu}, 1998$; John and Buehler, 2004).

A global ozone data assimilation system combines a global forecast model with ozone observations to produce a global gridded ozone analysis. The ozone forecast can fill in where observations are lacking, and aids in data quality control by providing a realistic background field. The observations can correct forecast errors, thereby providing accurate ozone initial conditions for the next forecast and analysis cycle. In addition to improving derived forecast products such as surface ultraviolet (UV) indices (Long et al., 1996), ozone assimilation and forecasting improve model stratospheric heating rates (and hence temperatures) and can be used to diagnose transport in the lower stratosphere, thereby improving wind assimilation (Peuch et al., 2000; Jang et al., 2003). These and other motivations for ozone assimilation, as well as previous work on the problem, are summarized by Rood (2005). More recent work has focused on the assimilation of new stratospheric ozone observations to improve the ozone analysis (e.g., Stajner and Wargan, 2004; Wargan et al., 2005; Stajner et al., 2006), and generation of multidecadal ozone reanalysis fields (Dethof and Holm, 2004; Oikonomou and O'Neill, 2006). Ozone data assimilation has also been used recently to evaluate different parameterizations of stratospheric ozone photochemistry (Geer et al., 2007).

Published by Copernicus GmbH on behalf of the European Geosciences Union. 


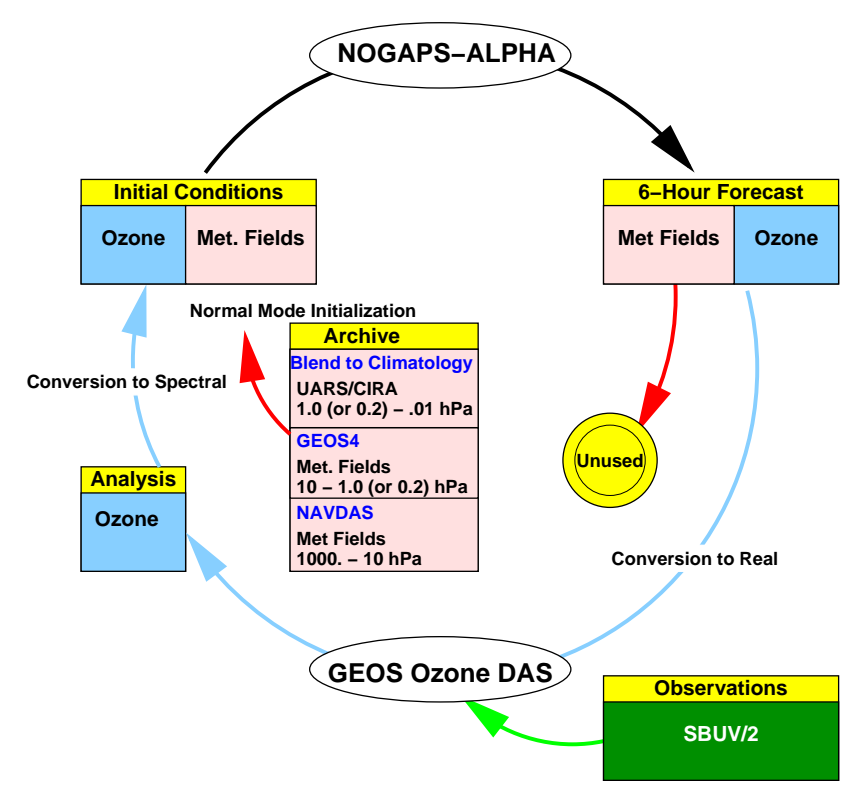

Fig. 1. Schematic depiction of a GOATS cycle. The two main components are NOGAPS-ALPHA (ozone forecast) and GEOS ozone DAS (ozone analysis). SBUV/2 layer ozone observations are assimilated into the cycle. The ozone fields continue through the cycle, however, the meteorological fields are re-initialized every $6 \mathrm{~h}$.

In improving stratospheric assimilations further, Rood (2005) concludes that details of the various assimilation algorithms are now secondary considerations compared to the more general issues of identifying and eliminating model/data biases and (relatedly) improving physical parameterizations (see also Povalarapu et al., 2005). We focus on those broader issues here in a series of experiments with an ozone assimilation system. Specifically, we investigate how the assimilation system responds to improvements in ozone "physics" by comparing results between experiments with and without a parameterization of ozone photochemistry in the forecast model. Output from each assimilation run is analyzed objectively using standard output parameters, such as mean and standard deviation (SD) of the innovations (observation minus forecast residuals). Additional experiments with and without parameterized ozone photochemistry examine how the mean innovations (i.e., the bias between the ozone forecast model and ozone observations) respond when fed with unbiased, then biased versions of the same set of satellite ozone observations.

We begin by describing our ozone assimilation system (Sect. 2), including a brief summary of the observations (Sect. 2.3), and assimilation experiments (Sect. 2.4). We present results of the experiments in Sect. 3 and the discussion of the results in Sect. 4 followed by the conclusions in Sect. 5.

\section{Global Ozone Assimilation Testing System}

To allow us to develop and refine an ozone assimilation and forecasting capability, we have developed a Global Ozone Assimilation Testing System (GOATS), depicted schematically in Fig. 1. GOATS couples the Goddard Earth Observing System (GEOS) ozone data assimilation system (DAS) with the NOGAPS-ALPHA (Navy Operational Global Atmospheric Prediction System - Advanced Level Physics with High Altitude) global forecast model. The components are discussed in more depth in Sects. 2.1 and 2.2, respectively. (Note that by using the GOATS we were quickly able to develop and refine key aspects of ozone assimilation while the Navy's operational NAVDAS (Naval Research Laboratory Atmospheric Variational Data Assimilation System) was being extended to higher altitudes. We are now beginning ozone assimilation research using NAVDAS.)

To start each 6-h analysis cycle, the NOGAPS-ALPHA General Circulation Model (GCM) is initialized with archived meteorological fields produced from the operational NOGAPS using the Naval Research Laboratory (NRL) Atmospheric Variational Data Assimilation System (NAVDAS). This approach simplifies the ozone assimilation by avoiding a complete meteorological assimilation for each model run. This simplification offers two advantages. First, it decouples the meteorological assimilation from the ozone assimilation, enabling us to focus on the parameters relevant to ozone. Second, it more easily facilitates the integration of the GEOS ozone DAS into the GOATS.

GOATS is similar to the off-line ozone data assimilation systems (see, e.g., Stajner et al., 2001) in that the meteorological analysis is independent of the ozone assimilation, however, GOATS follows the approach of Stajner et al. (2006), where the full GCM, rather than an ozone transport model, is used to dynamically advect ozone to the next analysis time. This means that GOATS has some advantages as well as disadvantages over a typical off-line ozone DAS. Advantages include the ability to influence model dynamics by changing shortwave heating and longwave cooling due to ozone. In all the GOATS results shown here, this interaction of ozone with dynamics through shortwave radiative heating and longwave cooling was activated, however the effects are not discussed in this paper. Another advantage for GOATS is that time interpolation of the meteorological analyses is not necessary, as the dynamical model predicts the meteorological fields along with the ozone at each model time step. The potential improvements in constituent transport from using GCM winds are discussed by Rood (2005).

A disadvantage for GOATS is that the dynamical model must be initialized at the start of each analysis cycle. This is an important consideration for GOATS because the current NOGAPS operational analyses are capped at $10 \mathrm{hPa}$. As shown schematically in Fig. 1, we circumvent this restriction in the GOATS by using GEOS4 (Goddard Earth Observing System version 4) meteorological analyses from $10-0.2 \mathrm{hPa}$ 
or from $10-1.0 \mathrm{hPa}$. Above the top analysis level, meteorological fields from the top analysis level are blended with climatological fields from UARS (Upper Atmosphere Research Satellite; Swinbank and Ortland, 2003) and CIRA (COSPAR International Reference Atmosphere; Fleming et al., 1990) as described in Eckermann et al. (2004). These global meteorological fields are then balanced using the NOGAPS-ALPHA Nonlinear Normal Mode Initialization (NNMI) scheme, before starting the forecast. Section 3.3 examines the effects of lowering the top GEOS4 analysis level from $0.2 \mathrm{hPa}$ to $1.0 \mathrm{hPa}$ and eliminating the NNMI.

Figure 1 illustrates a GOATS 6-h analysis cycle. The initial meteorological fields are set as described above, while ozone is taken from the previous GOATS ozone analysis (or from zonal-mean climatology for the first cycle). The fields are advanced $6 \mathrm{~h}$ using the NOGAPS-ALPHA GCM. The 6-h ozone forecast is saved on the model's grid at all levels using the spectral coefficients. An offline code transforms the data from spectral to real space, providing ozone mixing ratios on a Gaussian latitude-longitude grid as the "background" fields for the data assimilation. These background fields are then read into the GEOS ozone DAS, where they are statistically combined with all SBUV/2 (Solar Backscatter Ultraviolet Radiometer-2) data that occur within a 6-h window centered on the analysis time: these observations are discussed further in Sect. 2.3. The resulting analyzed ozone fields are transformed back into spectral coefficients that provide the initial ozone field for the next 6-h cycle, while the meteorological fields for the next cycle are again provided from archived NAVDAS and GEOS4 analyses. Note that archived GEOS ozone analyses are not used in GOATS.

Since we start GOATS with zonal-mean climatological ozone, it is necessary to determine the spin-up time required for this dependence on the zonal-mean ozone initial condition to be eliminated. Several tests compared assimilation runs initialized with both climatology and with a 3-D analysis provided by the operational GEOS ozone DAS. As in Geer et al. (2006), we found that ten to fifteen days of spinup time were sufficient to eliminate most of the dependence on initial conditions. When showing time average fields, we begin averaging 10 days after the GOATS initial time to suppress any significant influence from the initial condition.

Output from the GOATS runs includes the ozone analysis, 6-hourly ozone forecast, and the standard diagnostics provided by the GEOS ozone DAS. The latter include differences between the incoming observations and the background forecast $(\mathrm{O}-\mathrm{F}$, or innovations). The mean and standard deviation of the $\mathrm{O}-\mathrm{F}$ are used extensively to monitor the agreement between model and observations (Stajner et al., 2004).

\subsection{GEOS ozone DAS}

The statistical analysis system, which is used to assimilate ozone observations within the GOATS, was developed at
NASA's Goddard Space Flight Center as part of the Goddard Earth Observing System Data Assimilation System (GEOSDAS). This three-dimensional (3-D) ozone assimilation system has been used in a wide variety of applications, assimilating data from nadir-sounding instruments: SBUV/2 and Total Ozone Mapping Spectrometer (TOMS); and limbsounding instruments: Microwave Limb Sounder (MLS), Michelson Interferometer for Passive Atmospheric Sounding (MIPAS), Polar Ozone and Aerosol Monitor (POAM), and Improved Limb Atmospheric Spectrometer-II (ILASII). Detailed descriptions of the assimilation system, error modeling, and applications are provided in Riishøgaard et al. (2000), Stajner et al. (2001, 2004), Stajner and Wargan (2004), Wargan et al. (2005), and Stajner et al. (2006). The GEOS ozone DAS combines ozone observations with a background 3-D ozone field from a forecast model, using the Physical-space Statistical Analysis Scheme (PSAS) described by Cohn et al. (1998).

For the following experiments, the ozone analysis horizontal grid resolution was set to $1.5^{\circ}$ by $1.5^{\circ}$ (240 longitudes by 121 latitudes). This nearly matches the NOGPAP-ALPHA T79 horizontal resolution (240 longitudes by 120 latitudes on the quadratic Gaussian grid) that was used with the GOATS.

\subsection{NOGAPS-ALPHA}

Operational global NWP at the Fleet Numerical Meteorology and Oceanography Center (FNMOC) is provided by the Naval Research Laboratory's (NRL) Navy Operational Global Atmospheric Prediction System (NOGAPS: Hogan and Rosmond, 1991). The NOGAPS Eulerian spectral model currently uses a T239L30 formulation operationally, and these $30 \sigma$ levels are depicted in Fig. 2, both the interface (half) levels (panel a) and the profile of corresponding layer thicknesses (black curve in panel c).

A comparison of Figs. 2a and d shows that ozone mixing ratios peak at the uppermost thick diffused layers of this L30 model, which makes it unsuitable for ozone assimilation. Thus, GOATS uses an advanced-level physics, high-altitude (ALPHA) nonoperational prototype of the NOGAPS spectral model, known as NOGAPS-ALPHA. Only those aspects of NOGAPS-ALPHA salient to GOATS are described in what follows, since more detailed descriptions of NOGAPS-ALPHA have been provided in a number of recent publications (Eckermann et al., 2004, 2006; McCormack et al., 2004; Allen et al., 2006).

\subsubsection{Model resolution}

We typically run NOGAPS-ALPHA using an L60 hybrid $\sigma-$ $p$ formulation whose layer thicknesses are shown in Fig. 2c (see also Eckermann et al., 2006). However, the GEOS ozone DAS was developed and tuned within the framework of the specific L55 hybrid $\sigma-p$ levels of the Version 4 Goddard Earth Observing System (GEOS4) model (Bloom et al., 


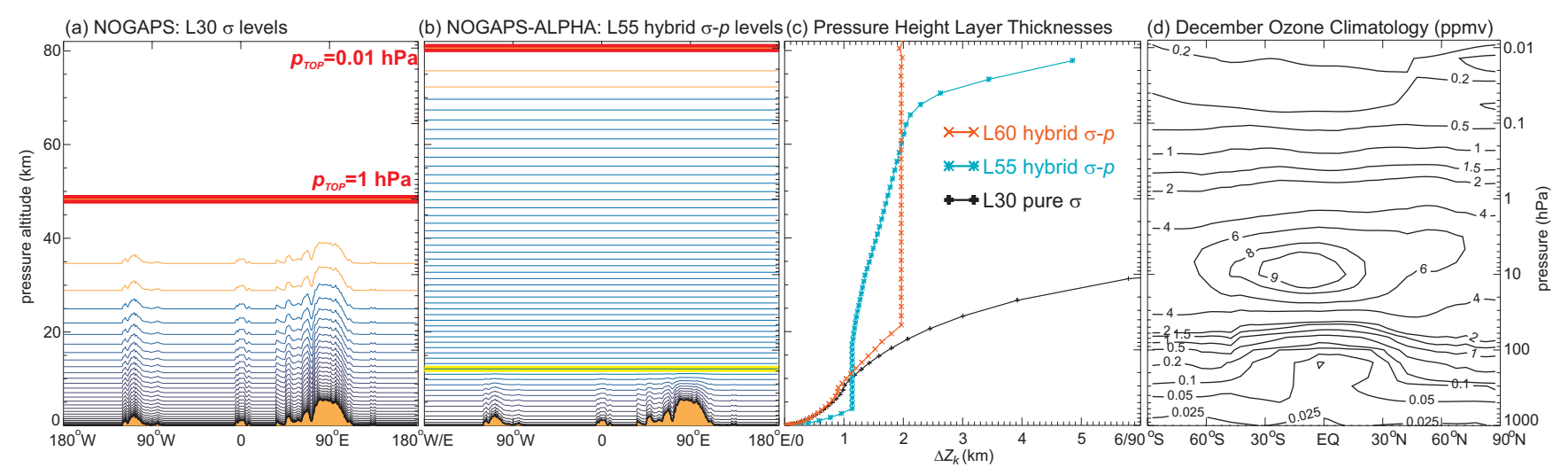

Fig. 2. Model half levels around $34.5^{\circ} \mathrm{N}$ latitude circle for (a) NOGAPS L30 (pure $\sigma$ levels) and (b) NOGAPS-ALPHA L55 levels (hybrid $\sigma-p$ levels). Orange levels demark heavily diffused upper layers, red line shows top half-level pressure $p_{\mathrm{TOP}}$, yellow line in (b) shows lowest isobaric half level $(177 \mathrm{hPa})$. (c) Model layer pressure-height thicknesses $\Delta Z_{k}$ for these model formulations, as well as L60 NOGAPS-ALPHA levels. (d) Zonal-mean daytime ozone volume mixing ratio climatology (ppmv) for December as function of latitude and pressure.

2005). Thus, to simplify interfacing the GEOS ozone DAS to NOGAPS-ALPHA, we built these same L55 $\sigma-p$ levels into NOGAPS-ALPHA, with some minor top level differences due to NOGAPS use of a finite top level pressure $p_{\text {TOP }}$ within its hybrid coordinate formulation. Those L55 NOGAPS-ALPHA half levels are shown in Fig. 2b, and the corresponding layer thicknesses in Fig. 2c. These L55 levels span the full depth of the stratospheric ozone layer with good vertical resolution throughout.

To reduce the computational burden, in this test environment we ran the NOGAPS-ALPHA at a T79 spectral resolution in all the GOATS experiments reported here.

\subsubsection{Prognostic ozone}

NOGAPS-ALPHA initializes a three-dimensional global ozone mixing ratio field $r$ that is subsequently advected spectrally and can also be photochemically updated (see, e.g., McCormack et al., 2004, 2006). In the GOATS, the prognostic ozone is initialized with the latest assimilated ozone at the start of each $6 \mathrm{~h}$ forecast (see Fig. 1).

In common with other NWP ozone DASs, for photochemistry NOGAPS-ALPHA uses a linearized parameterization of rates of gas-phase ozone photochemical production $P$ and loss $L$, formulated mathematically (Cariolle and Déqué, 1986) as

$$
\begin{aligned}
(P-L)=(P-L)_{o} & +\left.\frac{\partial(P-L)}{\partial r}\right|_{o}\left(r-r_{o}\right) \\
& +\left.\frac{\partial(P-L)}{\partial T}\right|_{o}\left(T-T_{o}\right) \\
& +\left.\frac{\partial(P-L)}{\partial \Sigma}\right|_{o}\left(\Sigma-\Sigma_{o}\right)
\end{aligned}
$$

Here $r, T$ and $\Sigma$ are the current model values of ozone mixing ratio, temperature and ozone column density, respectively. The "o" subscripts denote values at a reference (or equilibrium) state. The reference states $r_{o}, T_{o}$ and $\Sigma_{o}$ are specified by zonal-mean climatologies, while the four reference state photochemical coefficients in Eq. (1) are provided as zonal-mean lookup tables by the photochemistry scheme. Note that this linearized ozone photochemistry formulation is solidly based on the detailed photochemistry of ozone (see Sect. 2.1 of McCormack et al., 2006, and references therein). Thus the photochemical damping dependences seen here in the upper stratosphere should also occur in assimilation systems containing complete specifications of multireaction ozone photochemistry. NOGAPS-ALPHA incorporates and can use any one of the various linearized ozone photochemistry schemes currently in use by the world's major NWP/DA centers and some climate models. Preliminary assessments and intercomparisons of some of these schemes in NWP/DA applications have been provided by McCormack et al. (2004, 2006) and Geer et al. (2007). A major motivation for our development of GOATS is to objectively benchmark the performance of photochemistry schemes in a realistic high-altitude prototype ozone DA system, prior to implementation of ozone in operational DA systems, such as the NRL Atmospheric Variational Data Assimilation System (NAVDAS: Daley and Barker, 2001).

NRL has developed a scheme based on output from their zonally-averaged CHEM2D model (McCormack and Siskind, 2002). This CHEM2D-OPP (Ozone Photochemistry Parameterization) scheme is described by McCormack et al. (2006), and has been implemented operationally in the National Centers for Environmental Prediction Global Forecast System (NCEP GFS) and transitioned to FNMOC for the operational NOGAPS. CHEM2D-OPP was used for all 
Table 1. Mid-September 2002 values of SBUV/2 observations for layers 3-12 used in scaling vertical profile plots.

\begin{tabular}{llr}
\hline $\begin{array}{l}\text { Layer } \\
\text { Number }\end{array}$ & $\begin{array}{l}\text { Pressure } \\
\text { Range }(\mathrm{hPa})\end{array}$ & $\begin{array}{r}\text { Typical } \\
\text { Value (DU) }\end{array}$ \\
\hline 3 & $63.3-127$ & 45 \\
4 & $31.7-63.3$ & 55 \\
5 & $15.8-31.7$ & 65 \\
6 & $7.92-15.8$ & 46 \\
7 & $3.96-7.92$ & 24 \\
8 & $1.98-3.96$ & 10 \\
9 & $0.99-1.98$ & 3.3 \\
10 & $0.495-0.990$ & 0.96 \\
11 & $0.247-0.495$ & 0.29 \\
12 & $0.0-0.2467$ & 0.12 \\
\hline
\end{tabular}

the GOATS results with parameterized ozone photochemistry presented in Sect. 3 .

In the present study, the GOATS assimilates SBUV/2 observations during the period of September-October 2002. An examination of the individual terms in the photochemistry parameterization shows that the second term on the right hand side of Eq. (1) dominates the photochemistry component of NOGAPS-ALPHA at altitudes above $10 \mathrm{hPa}$ during this period. This term acts as a photochemical relaxation rate, $\tau_{O_{3}}=-\left[\left.\frac{\partial(P-L)}{\partial r}\right|_{o}\right]^{-1}$ (see Cariolle and Déqué, 1986; McCormack et al., 2006), that draws the forecasted ozone mixing ratio, $r$, toward the model's specified ozone reference state, $r_{o}$. The CHEM2D-OPP photochemical relaxation rates for September are shown in Fig. 3b.

In NOGAPS-ALPHA, the ozone reference state, $r_{o}$, is specified using an amalgam of the Fortuin and Kelder (1998) zonal-mean climatology at altitudes below $0.3 \mathrm{hPa}$, and longterm diurnally-averaged output from the CHEM2D model above (see McCormack et al., 2006, for details). Note that the Fortuin-Kelder climatology is heavily weighted with SBUV data, and thus is a good match for our GOATS SBUV/2 assimilation experiments. This NOGAPS-ALPHA zonal-mean ozone reference state for September is shown in Fig. 3a.

\subsection{SBUV/2 observations}

All the GOATS experiments that follow assimilate SBUV/2 ozone observations. The SBUV/2 instrument and the inverse model used to retrieve layer ozone values are described in Bhartia et al. (1996). The GEOS ozone DAS was developed using SBUV/2 observations (Riishøgaard et al., 2000; Stajner et al., 2001), and use of the innovation statistics from SBUV/2 ozone assimilation to monitor the DAS is described in Stajner et al. (2004). Following Stajner et al. (2001), we have used only SBUV/2 layers 3-12 in the GOATS along with the SBUV/2 total ozone column data. The pressure in- (a) Ozone Reference State $\boldsymbol{r}_{\boldsymbol{0}}$ (ppmv): September
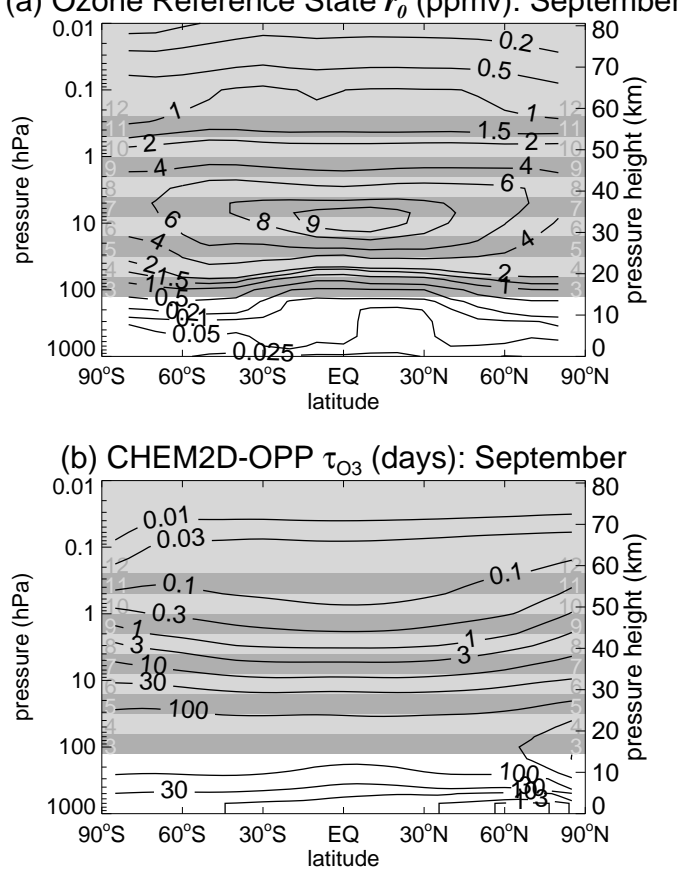

Fig. 3. (a) Ozone reference state, $r_{0}$ (ppmv) and (b) ozone photochemical relaxation time, $\tau_{O_{3}}$ (days) as function of latitude and pressure for September. The gray bands denote the SBUV/2 layers (see Table 1 for details).

tervals of the SBUV/2 layers 3-12 are given in Table 1 (see also Fig. 3). These SBUV/2 layers are similar to the Umkehr layers used for ground-based ozone observations.

As detailed further in Sect. 3.1.1, we used two operationally issued versions of SBUV/2 observations with different biases in the upper stratosphere. These were versions n16v61608 and n16v61814. The GOATS was run using each version in separate experiments to examine the effect of the bias on the ozone assimilation.

\subsection{GOATS experiments}

All the GOATS experiments shown here started on 1 September 2002, 00:00 UTC and ran with a 6-h ozone analysis cycle for up to 2 months. The global gridded ozone forecast and analysis fields were archived every $6 \mathrm{~h}$ along with the $\mathrm{O}-\mathrm{F}$ residuals. A reduction in the $\mathrm{O}-\mathrm{Fs}$ is a standard measure of improvement in a data assimilation system, and therefore the $\mathrm{O}-\mathrm{Fs}$ will be examined in detail in Sect. 3 .

The O-Fs can be examined globally or within a more restricted domain. For each level and region (usually global) we have computed an average (mean) $\mathrm{O}-\mathrm{F}$, or bias, and after subtracting the average from each value in the region, we have computed a standard deviation $(\mathrm{SD}) \mathrm{O}-\mathrm{F}$ over the same region.

The time period that we are examining was highlighted by the first observed major stratospheric warming in the 


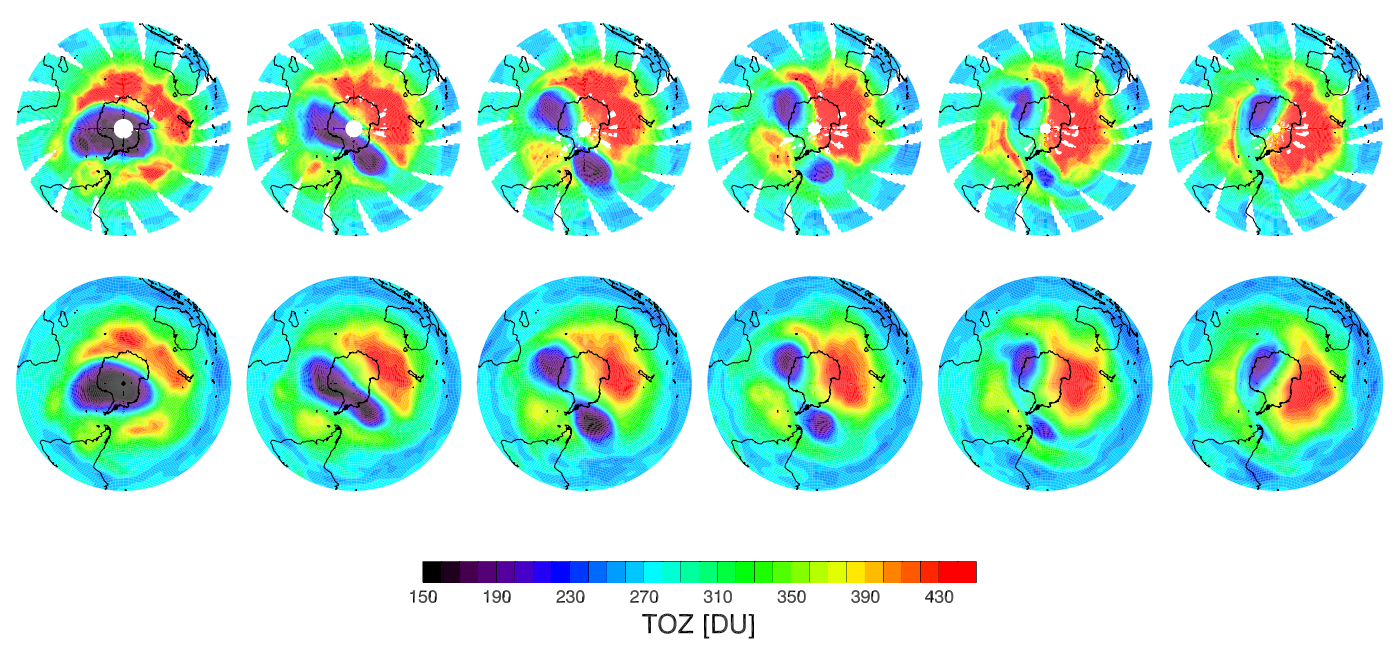

Fig. 4. Total ozone in the Southern Hemisphere for 20-30 September 2002 (48-h intervals) from the Total Ozone Mapping Spectrometer (TOMS; top row) and from the GOATS T79L55 run with CHEM2D-OPP chemistry (bottom row).

Southern Hemisphere (Newman and Nash, 2005; Allen et al., 2006). Ozone assimilation products during this time period have been examined by Geer et al. (2006). Figure 4 shows total ozone comparisons between the GOATS T79L55 ozone analyses (with CHEM2D-OPP activated) and TOMS (Total Ozone Mapping Spectrometer) during the warming event. The GOATS analyses capture the total ozone morphology of this period including the splitting of the ozone hole into two pieces on the 24th, the return to a single smaller ozone hole on the 30th, and the ridges of high ozone surrounding the ozone hole. These maps agree well with the SBUV/2 total ozone maps analyzed for this period by Kondragunta et al. (2005). Note that the GOATS low total ozone values ( $\sim 150 \mathrm{DU})$ on 20 September 2002 are produced by the assimilated SBUV/2 observations that often see into the disturbed low ozone region during the first 20 days of the assimilation.

In the next section we provide more quantitative assessments of GOATS performance. Examining GOATS analyses during this highly dynamic period will provide a stringent test of the quality of the analyses.

\section{Results}

This section describes some of the results from experiments performed with the GOATS. We first examine how the mean ozone $\mathrm{O}-\mathrm{Fs}$ depend on parameterized chemistry and observation biases. Then we examine how the SD O-Fs can be reduced with the addition of parameterized chemistry. Next we examine how biases can affect photochemical parameterizations in which reference climatologies are updated adaptively using the assimilated fields from earlier times. Finally, we examine how improved mesospheric dynamics improve the ozone assimilation.

\subsection{O-Fs and parameterized chemistry}

As shown by Stajner et al. (2004), the observation-minusforecast $(\mathrm{O}-\mathrm{F})$ innovations can be useful for diagnosing the performance of an operational ozone DAS. Here, we examine the response of the O-Fs to changes in the forecast model, beginning with changes occurring when parameterized ozone photochemistry (CHEM2D-OPP) is added to the forecast model.

Figure 5 shows global average O-F times series for SBUV/2 layer $8(1.98-3.96 \mathrm{hPa})$ for two experiments: one with and one without parameterized ozone photochemistry. Since $\tau_{O_{3}} \sim 1$ day in layer 8 (Fig. 3b), one would expect model chemistry to play a role during each 6-h GOATS cycle. As stated in Sect. 2.4, at each analysis time the 6-h mean of the O-Fs in Fig. $5 \mathrm{~b}$ has been subtracted before calculating the standard deviation values shown in Fig. 5a. Separating the O-Fs into a mean and a standard deviation is useful because, as will be shown, each quantity responds to model changes in a different way. While parameterized chemistry has reduced the SBUV/2 layer 8 global standard deviation of the $\mathrm{O}-\mathrm{Fs}$ at all times, the mean of the $\mathrm{O}-\mathrm{Fs}$ shows slightly larger absolute values for the parameterized chemistry case and the mean $\mathrm{O}-\mathrm{Fs}$ are increasing towards the end of the integration, which indicates increasing disagreement between the observations and the model forecast. Compared with a typical value for the layer of $\sim 10$ DU (see Table 1), the differences between the mean $\mathrm{O}-\mathrm{Fs}$ in the two cases are relatively small.

\subsubsection{Mean O-F}

This section examines how parameterized chemistry and data biases affect the mean $\mathrm{O}-\mathrm{F}$. We have found that early versions of the SBUV/2 data were biased roughly $10 \%$ high 
(a)

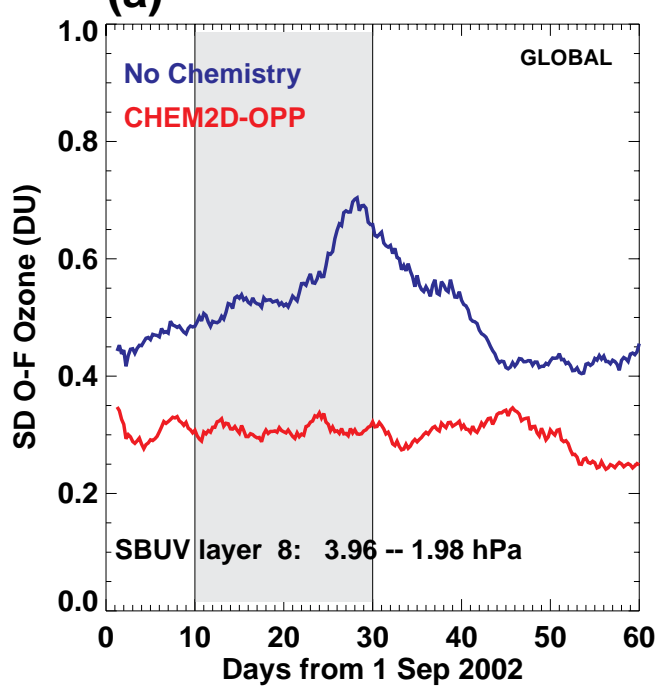

(b)

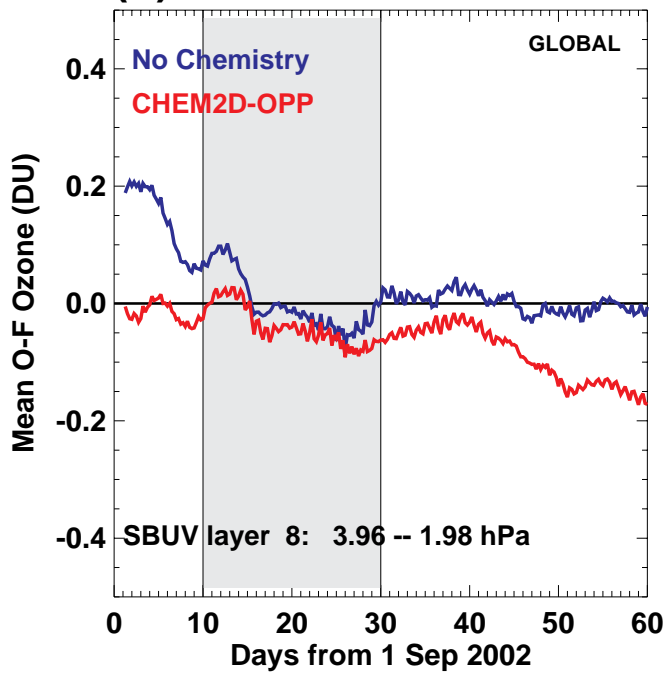

Fig. 5. Comparisons of SBUV/2 layer 8, global averaged (a) standard deviation and (b) mean O-Fs (DU) for GOATS without (blue curve) and with (red curve) an ozone photochemistry parameterization. A 2-day boxcar filter has been applied to the 6-hourly global average O-Fs to reduce diurnal fluctuations, and the initial day is not plotted. The gray shaded regions denote the domain that is time averaged in later figures. SBUV/2 layer 8 represents the vertically integrated ozone from $3.96-1.98 \mathrm{hPa}$, with an typical global average September value of $\sim 10$ DU.

in the upper SBUV/2 layers. For example, Fig. 6 shows layer 8 ozone as a function of latitude from two versions of SBUV/2 for 15 September 2002, along with zonal-mean September values from the Fortuin and Kelder (1998) climatology, which NOGAPS-ALPHA uses for $r_{o}$ in Eq. (1). The latitudinal structures in the two SBUV/2 data sets are very similar except for an offset, with n16v61814 matching closely with the climatology and n16v61608 biased high. We refer to the SBUV/2 version n16v61608 as "biased", or "high biased" in the discussions and figures below, though for the following experiments we are only interested in the relative difference between the two SBUV/2 data sets and the NOGAPS-ALPHA climatology. We ran the GOATS in separate experiments using each data set. The high bias of the earlier version allows us to test how data biases affect the mean O-Fs.

Figure 7 shows the mean layer $8 \mathrm{O}-\mathrm{F}$ time series for GOATS runs using the different SBUV/2 data sets. The O-Fs with chemistry (Fig. 7a) are large for the n16v61814 observations that are biased high with respect to the model ozone climatology in Fig. 6. However, without chemistry (Fig. 7b) the mean O-Fs converge to near zero, independent of the input data bias. These latter results make sense for global averaged fields because the forecast model without chemistry can only change ozone mixing ratios by advection. In a global average there is no net change due to horizontal advection and the vertical mass flux must average to zero. It is still possible to change global average ozone if the vertical ozone gradients are correlated with the vertical motion (a non-zero global-mean vertical eddy ozone flux gradient),

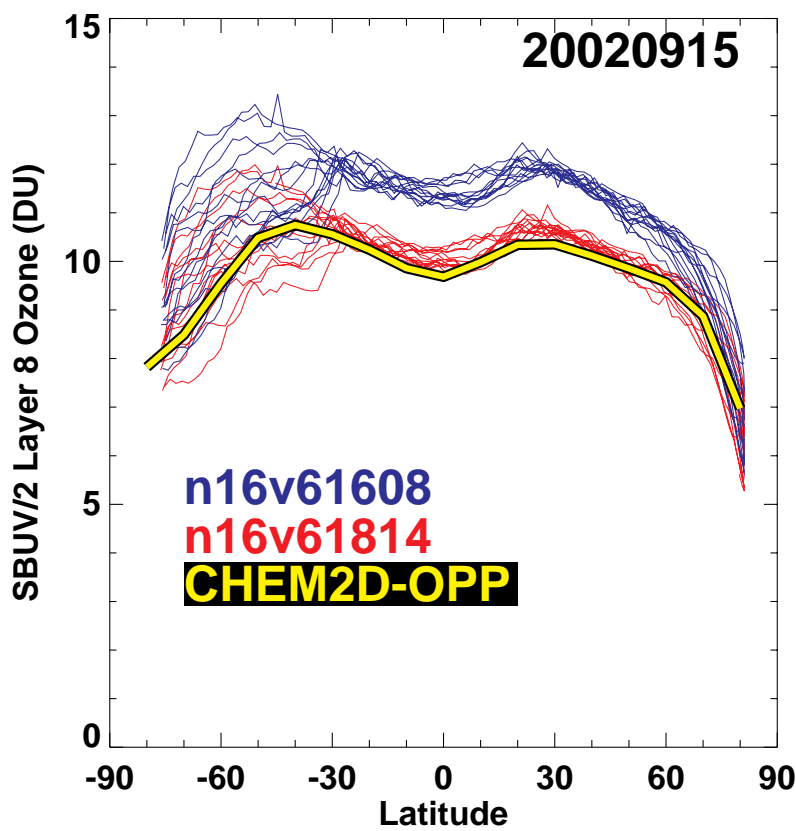

Fig. 6. SBUV/2 layer 8 ozone observations (DU) on 15 September 2002 plotted as a function of latitude for versions n16v61608 (blue curves) and version n16v61814 (red curves). Also plotted are corresponding, vertically-integrated over SBUV/2 layer 8, September background ozone values, $r_{o}$, based on the Fortuin and Kelder (1998) zonal-mean ozone climatology (yellow curve) used in the CHEM2D-OPP scheme in Eq. (1); see Fig. 3a. 
however, these changes are often small, as will be seen in the vertical profile plots below. Thus, in experiments without ozone chemistry, the forecast model for global averaged ozone in a given layer is close to persistence (no net change over the 6-h forecast), and each ozone analysis ratchets the global averaged ozone closer to the global average of the observations, reducing the $\mathrm{O}-\mathrm{Fs}$ to near zero (Fig. 7b). In contrast, for the experiments with chemistry, the model moves the global averaged ozone in the upper stratosphere closer to the global average of the model ozone reference state $r_{o}$ during each 6-h forecast. Thus, with chemistry, the assimilation system is able to maintain a difference between the biased input data and the model forecast (Fig. 7a).

While the global mean $\mathrm{O}-\mathrm{Fs}$ without chemistry converge to the same near zero value regardless of the data bias (Fig. 7b), the two ozone analyses are very different. Figure 8 shows difference plots of the zonal mean analyses for 15 September 2002 for assimilations based on the two different SBUV/2 data products in Fig. 6. The input data bias between these two experiments produces only a small difference in the ozone analyses for GOATS runs with chemistry (Fig. 8a), whereas the ozone analyses without chemistry incorporate much of the bias evident in the original data in Fig. 6.

To assess changes at all the SBUV/2 layers, hereafter O-Fs over the time period 10-30 September 2002 (shaded gray in Fig. 5) are averaged and plotted as vertical profiles. The vertical profiles are all normalized by the same midSeptember SBUV/2 values (Table 1) to compensate for the small absolute $\mathrm{O}-\mathrm{F}$ values at upper levels.

Figure 9 plots vertical profiles of mean ozone O-Fs averaged over 10-30 September 2002. When globally averaged (Figs. 9a and 9b) the O-Fs without chemistry (blue curves) are close to zero, particularly in layers 7-10, and independent of whether the input observations are biased (Fig. 9a) or not (Fig. 9b). The global bias in the input data can be seen by examining the yellow curves in Figs. 9a and b, which show the difference between the observations and the September zonal-mean ozone climatology, $r_{o}$ (see Fig. 3a). Since this ozone climatology is unchanged for the experiments shown in Figs. 9a and b, differences in the yellow curve between the two panels reflect the bias between the two SBUV/2 data sets. This data bias difference is mostly confined to layers 7 and above since the yellow curves in layers 3-6 are almost identical in Figs. 9a and b. In Fig. 9a the bias between the observation (n16v61608) and the model's ozone climatology in layers $7-10$ (yellow curve) is $\sim 10-15 \%$, while in Fig. $9 \mathrm{~b}$ the bias between the observations (n16v61814) and the model's ozone climatology in layers 7-10 (yellow curve) is less than 5\%. As expected from Fig. $3 \mathrm{~b}$ the fast photochemical time scales $\tau_{\mathrm{O}_{3}}=-\left[\left.\frac{\partial(P-L)}{\partial r}\right|_{o}\right]^{-1}$ at upper levels relax the mean $\mathrm{O}-\mathrm{Fs}$ with chemistry (red curves) in Figs. 9a and b toward the chemistry's reference state climatology $r_{o}$ (yellow curves) in the upper stratosphere.
Figures $9 \mathrm{c}$ and $\mathrm{d}$ plot the mean $\mathrm{O}-\mathrm{Fs}$ averaged over the equatorial region (between $\pm 15^{\circ}$ latitude). This time the $\mathrm{O}-\mathrm{Fs}$ for the experiments without chemistry (blue curves) are not constrained to be close to zero, as there can be a net advective change in a localized region. Note that both blue curves (no chemistry run) in Figs. 9c and d are essentially the same, so that, as in the globally averaged case, the regionally averaged $\mathrm{O}-\mathrm{Fs}$ are independent of the input data bias since equatorially averaged advection patterns are the same in both experiments. This makes sense because the advection-only ozone forecast model depends only on ozone gradients, not on the mean ozone value. With the unbiased observations, the $\mathrm{O}-\mathrm{Fs}$ with chemistry (red curve in Fig. 9d) move close to zero in layers 8-10 and again asymptote to the yellow curves at upper levels in both cases.

Figure 10 uses the same presentation as Fig. 9 for the southern and northern polar regions (upper and lower panels, respectively). The southern polar region is very dynamically active during this time period (Newman and Nash, 2005), so it is not surprising that even with the unbiased input data (Fig. 10b) the bias between the observations and the zonalmean reference climatology (yellow curve) is not close to zero. Even so, the mean $\mathrm{O}-\mathrm{Fs}$ improve significantly with the unbiased observations. Note that, unlike the global and equatorial averaged cases, the mean $\mathrm{O}-\mathrm{Fs}$ with chemistry (red curves) in the southern polar region do not adjust completely to the model chemistry. This is probably because the southern polar dynamics are far from a zonal mean at this time. Surprisingly, even though regionally (not globally) averaged and at a dynamically active time, the mean $\mathrm{O}-\mathrm{Fs}$ without chemistry in the southern polar region are very close to zero, indicating that the net advective ozone forcing in the model is small here. The northern polar region shows an example where adding chemistry, in addition to unbiased input data (Fig. 10d), significantly improves the mean O-Fs (red curve) over the case without chemistry (blue curve).

\subsubsection{Standard deviation of $\mathrm{O}-\mathrm{F}$}

Figure 5a showed some improvement in the SD O-F when using parameterized chemistry. Because dynamics are different at different latitudes, we expect the SD O-F will depend on latitude, and therefore this section focuses on the dependence of SD $\mathrm{O}-\mathrm{F}$ with and without parameterized ozone photochemistry in equatorial and southern polar latitudes.

Figure 11 shows the SD $\mathrm{O}-\mathrm{F}$ in the equatorial region using the unbiased SBUV/2 data. We find that adding chemistry reduces the SD O-F in layers $8-12$, with much of this reduction resulting from photochemistry reducing the forecast model variance: This can be seen by expanding the $\mathrm{O}-\mathrm{F}$ variance as:

$\overline{(O-F)^{\prime 2}}=\overline{O^{\prime 2}}+\overline{F^{\prime 2}}-2 \overline{\left(O^{\prime} F^{\prime}\right)}$,

where the primes denote fields after an area mean has been subtracted and the overbar denotes an area average. Dashed 

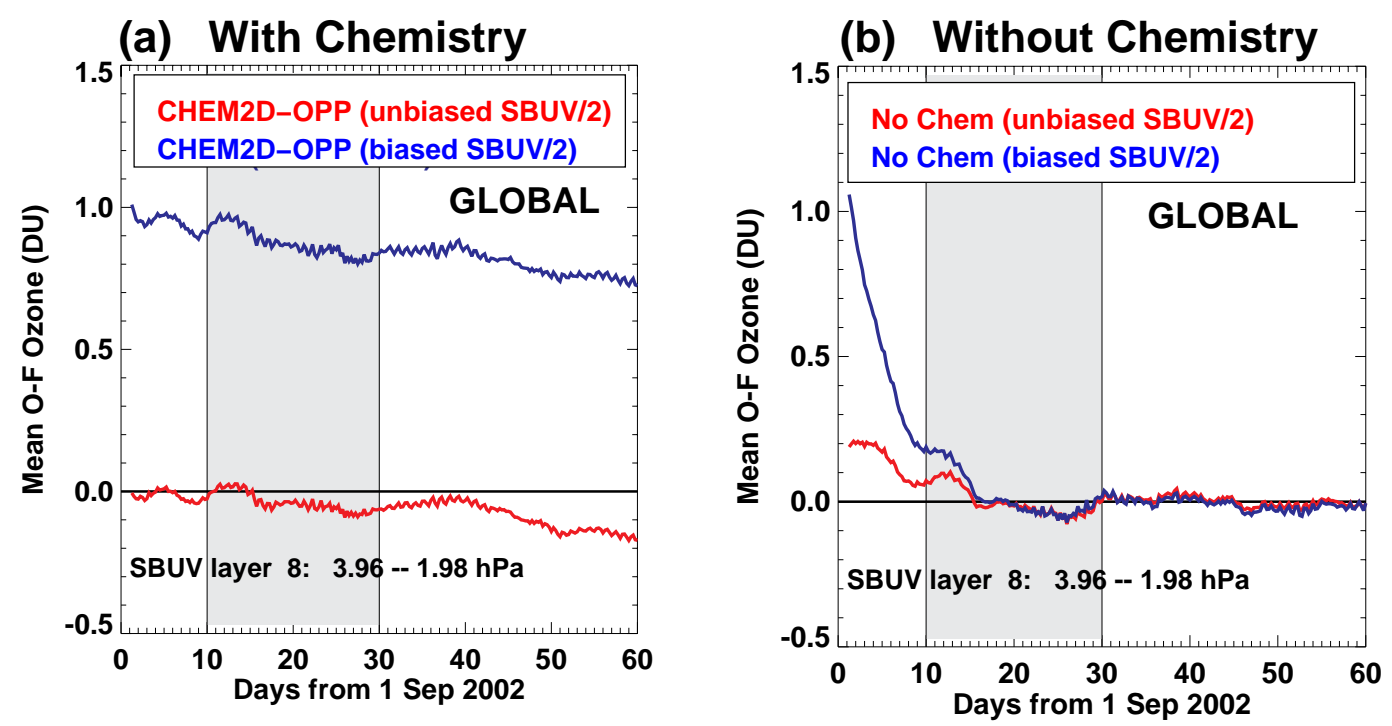

Fig. 7. Comparisons of SBUV/2 layer 8, global averaged mean O-Fs (DU) for GOATS runs (a) with and (b) without the ozone photochemistry parameterization (CHEM2D-OPP). The blue curves assimilated the high-biased (n16v61608) version of SBUV/2 observations. The red curves assimilated the more recent SBUV/2 n16v61814 observations. A 2-day boxcar filter has been applied to the 6-hourly global average $\mathrm{O}-\mathrm{Fs}$ to reduce diurnal fluctuations, and the initial day is not plotted. The gray shaded regions denote the domain that is time averaged and plotted in other figures. SBUV/2 layer 8 represents the vertically integrated ozone from 3.96-1.98 hPa, with a typical global average September value of $\sim 10 \mathrm{DU}$.
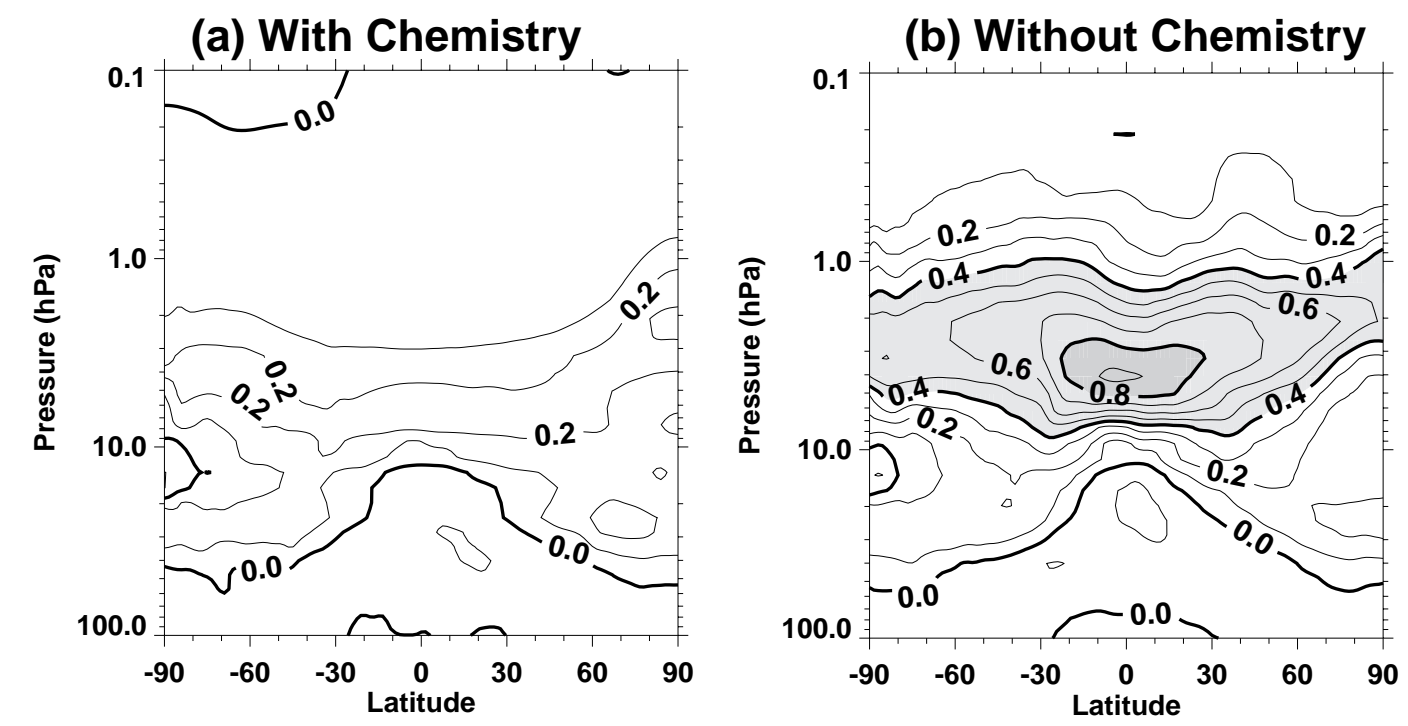

Fig. 8. Differences in zonal-mean ozone analysis fields on 15 September 2002 between GOATS assimilations of high-biased SBUV/2 observations (n16v61608) and unbiased SBUV/2 observations (n16v61814) for runs (a) with and (b) without the ozone photochemistry parameterization (CHEM2D-OPP). The contour interval is $0.1 \mathrm{ppmv}$.

curves in Fig. 11 show just the square root of the forecast model variance, $\left(\overline{F^{\prime 2}}\right)^{1 / 2}$, for runs with and without chemistry (red and blue dashed curves, respectively). The observed reduction of model standard deviation is equal to the reduction of SD $\mathrm{O}-\mathrm{F}$ at layers $8-10$, and this reduction of model standard deviation is even greater than the reduction of SD O-F for layer 11.
More detail is given in Table 2, where values for each term in Eq. (2) are calculated separately for layers 8-11. The variance, $\overline{O^{\prime 2}}$, of the SBUV/2 ozone observations, remains the same for the cases with and without chemistry. The variance, $\overline{F^{\prime 2}}$, of the 6-h model forecast is calculated by integrating the forecast model over the SBUV/2 layers and interpolating the forecast model to the SBUV/2 observation locations, 
(a)

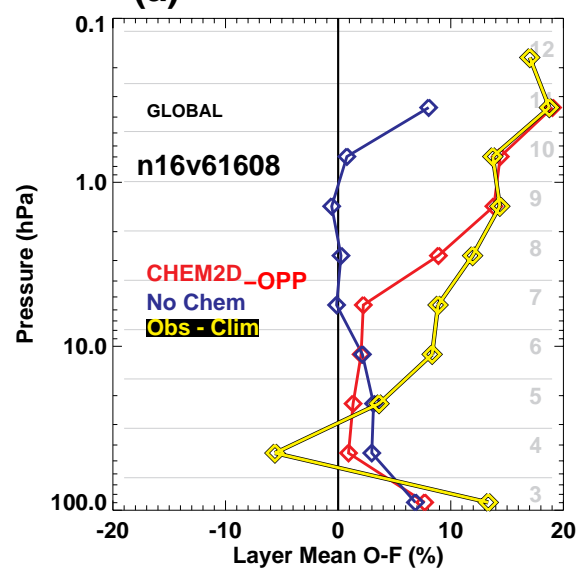

(c)

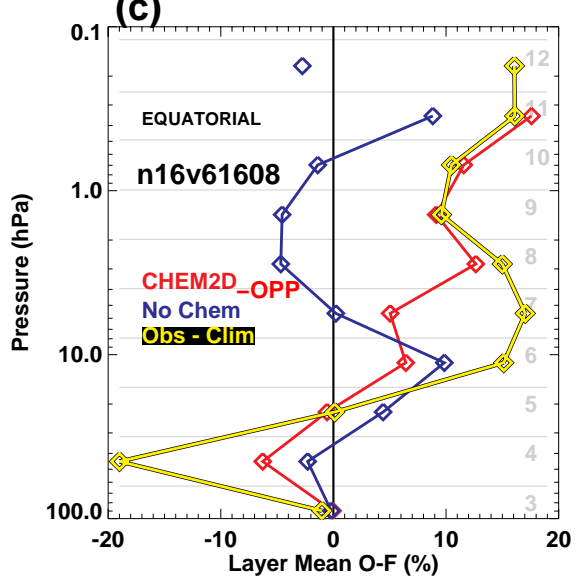

(b)
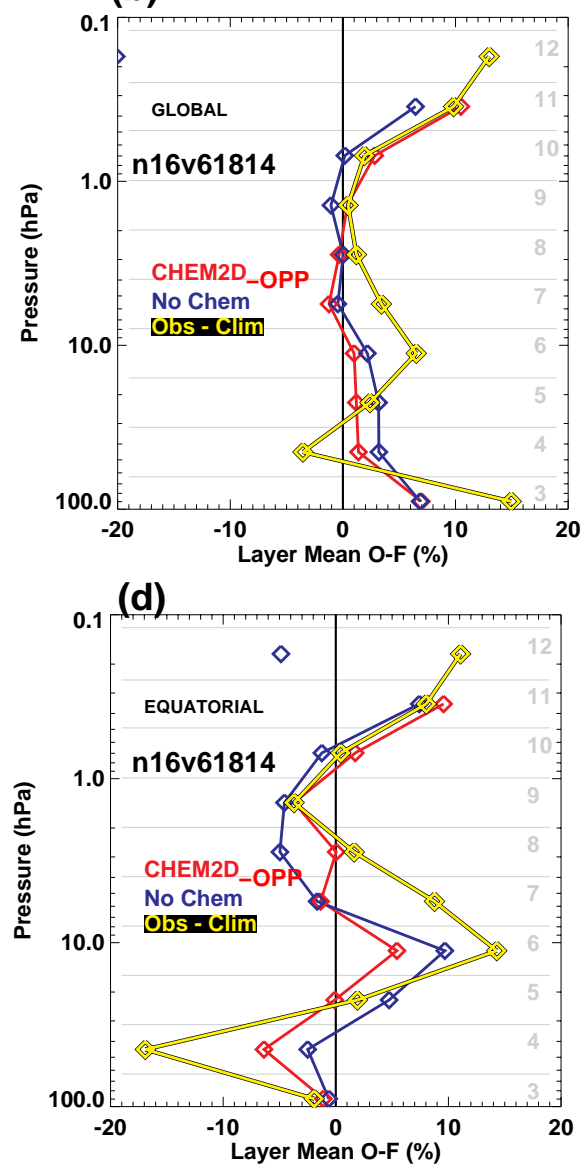

Fig. 9. Vertical profiles of ozone mean $\mathrm{O}-\mathrm{Fs}$ expressed as a percentage relative to the nominal mean values in Table 1, averaged over 10-30 September 2002 with (red curves) and without (blue curves) parameterized ozone photochemistry. Plots (a) and (c) show results from assimilating the earlier (high biased) version of SBUV/2 observations (n16v61608); plots (b) and (d) show results from assimilating the more recent (unbiased) version of SBUV/2 (n16v61814). Plots (a) and (b) are global averages, plots (c) and (d) are equatorial averages $\left(15^{\circ} \mathrm{S}-15^{\circ} \mathrm{N}\right)$. Also plotted is the mean difference between SBUV/2 observations and the Fortuin and Kelder (1998) ozone climatology (yellow curve) for the corresponding data sets and regions. The gray horizontal lines mark the boundaries of the SBUV/2 layers (Table 1) labeled by the gray numbers on the right of each plot.

Table 2. $10-30$ September 2002 equatorial $\left( \pm 15^{\circ}\right.$ latitude) variances: $\overline{(O-F)^{\prime 2}}, \overline{F^{\prime 2}}, \overline{O^{\prime 2}}$, and $2 \overline{O^{\prime} F^{\prime}}$. Values in $\mathrm{DU}^{2}$ are scaled by $10^{4}$ for layer $11,10^{3}$ for layer 10 , and $10^{2}$ for layers 8 and 9 .

\begin{tabular}{rrrrrr}
\hline Exp & Layer & $\overline{(O-F)^{\prime 2}}$ & $2 \overline{O^{\prime} F^{\prime}}$ & $\overline{F^{\prime 2}}$ & $\overline{O^{\prime 2}}$ \\
\hline No Chem & 11 & 17.79 & 1.81 & 18.70 & 0.90 \\
Chem & 11 & 1.14 & -0.05 & 0.19 & 0.90 \\
No Chem & 10 & 18.45 & -0.51 & 17.74 & 0.20 \\
Chem & 10 & 0.36 & -0.03 & 0.13 & 0.20 \\
No Chem & 9 & 11.13 & -0.18 & 10.03 & 0.92 \\
Chem & 9 & 0.69 & 0.72 & 0.49 & 0.92 \\
No Chem & 8 & 46.65 & -5.41 & 36.83 & 4.41 \\
Chem & 8 & 7.62 & 1.54 & 4.75 & 4.41 \\
\hline
\end{tabular}

then calculating the variance of these integrated and interpolated values. The covariance, $\overline{\left(O^{\prime} F^{\prime}\right)}$, is calculated using the observations and the interpolated and layer-integrated model forecast values.

The most striking effect of adding chemistry to the assimilation system is the huge reduction of the forecast model variance. The covariance (which should be positive when the forecast and observations are correlated) is actually negative (anticorrelated) without chemistry for layers 8-9. With chemistry, in layers 8 and 9 , the (positive) covariance becomes the same order of magnitude as the forecast model and observation variance, thereby reducing via Eq. (2) $\mathrm{O}-\mathrm{F}$ variance in those layers.

Also plotted in Fig. 11 is the standard deviation of the observations, $\left(\overline{O^{\prime 2}}\right)^{1 / 2}$ (black curve). As seen in Fig. 11 (and the variances in Table 2), the SD O-F is larger than the SD O 

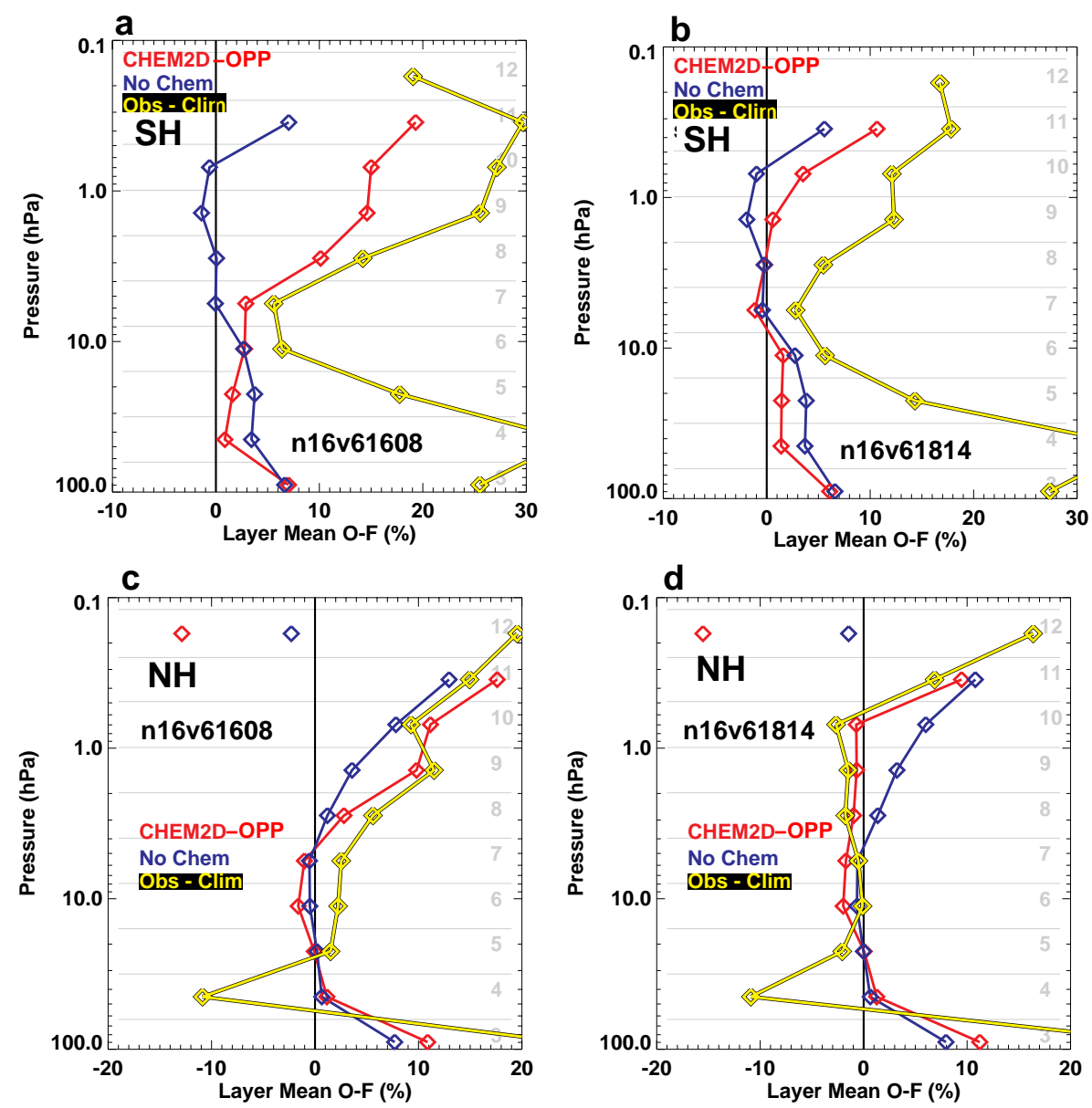

Fig. 10. Vertical profiles of ozone mean O-Fs averaged over 10-30 September 2002 with (red curves) and without (blue curves) parameterized ozone photochemistry. Plots (a) and (c) show results from assimilating the earlier (high biased) version of SBUV/2 observations (n16v61608); plots (b) and (d) show results from assimilating the more recent (unbiased) version of SBUV/2 (n16v61814). Plots (a) and (b) are averaged from $90^{\circ} \mathrm{S}-60^{\circ} \mathrm{S}$, plots (c) and (d) are averaged from $60^{\circ} \mathrm{N}-90^{\circ} \mathrm{N}$. Also plotted is the mean difference between SBUV/2 observations and the Fortuin and Kelder (1998) zonal-mean ozone climatology (yellow curve) for the corresponding data sets and regions. The gray horizontal lines mark the boundaries of the SBUV/2 layers (Table 1) labeled by the gray numbers on the right of each plot.

in layers $8-12$ for the experiment without chemistry. This means that a "flat" forecast, one without variance, would yield a better SD O-F (it would equal SD O in that case) than using the no chemistry forecasts. For the chemistry run, the SD O-F is about the same as SD O for layers 6-12, with slightly lower values in layers 8 and 9 . However, the equatorial region does not feature such large-amplitude planetary scale zonal ozone asymmetries found in the winter extratropics, and therefore these SD O-F values are less than $5 \%$ for layers 6-11.

These differences in forecast variance can be seen in the forecast ozone fields themselves (Fig. 12). Without chemistry (Fig. 12a), the ozone field shows much more smallscale structure and higher variability, with a difference between the maximum and minimum value over the field of 3.38 ppmv; with chemistry (Fig. 12b), the ozone field is noticeably smoother with a difference between the maxi- mum and minimum values over the field of 1.74 ppmv, about half of the range without chemistry. In agreement with Fig. 11, which shows a decrease of about a factor of 3 in time-averaged standard deviation of the ozone forecast for layer 9 when adding chemistry, the standard deviation of ozone along the equator at this one time in Fig. 12 decreases from $0.33 \mathrm{ppmv}$ to $0.11 \mathrm{ppmv}$ when chemistry is added. Note that the large amount of small-scale structure in the forecast ozone fields without chemistry (Fig. 12a) is likely a consequence of the GOATS cycle (Fig. 1), in which the model is continually adjusting to the 6 hourly re-initialization.

Figure 13 plots the SD O-F and the SD O for the southern polar region: Note the change in scale from Fig. 11. This period corresponds to the Southern Hemisphere's only observed major warming and so, not surprisingly, ozone shows large variance, especially in the lowest layers. At layer 3 the SD O-F is $20 \%$ compared to the SD O of near $75 \%$. The 


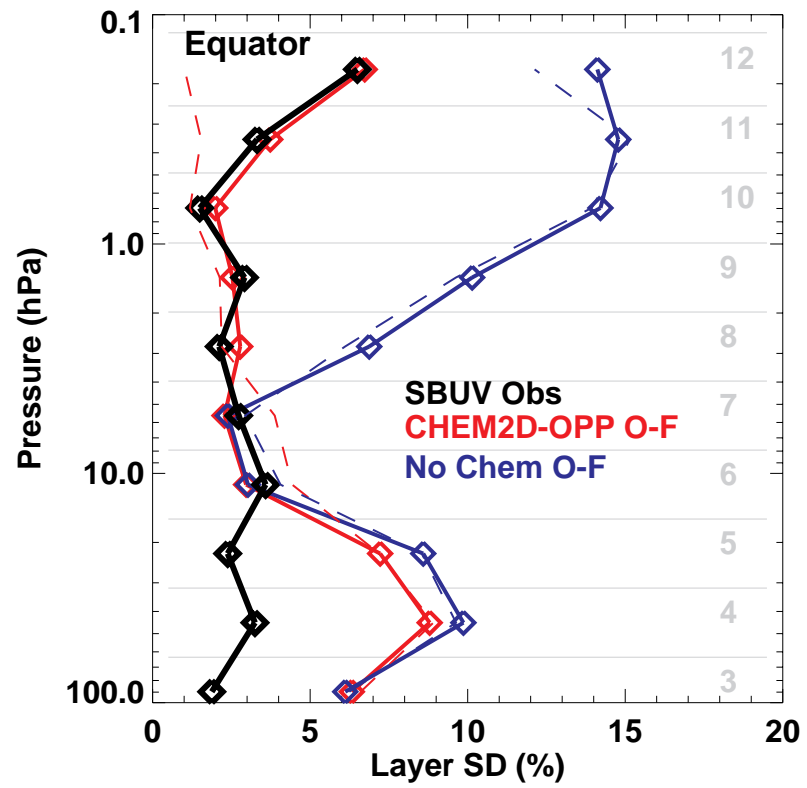

Fig. 11. Vertical profiles of the standard deviation of ozone $\mathrm{O}-\mathrm{Fs}$, $\left[\overline{(O-F)^{\prime 2}}\right]^{1 / 2}$, averaged over 10-30 September 2002 and within $\pm 15^{\circ}$ latitude with (red curve) and without (blue curve) parameterized ozone photochemistry. Both curves result from assimilating the unbiased SBUV/2 observations. The corresponding colored dashed lines plot the standard deviation of the ozone forecast interpolated to the observation locations, $\left(\overline{F^{\prime 2}}\right)^{1 / 2}$. The dashed lines are often close to the corresponding solid $\left[\overline{(O-F)^{\prime 2}}\right]^{1 / 2}$ curve. The black curve plots the standard deviation of the SBUV/2 observations, $\left(\overline{O^{\prime 2}}\right)^{1 / 2}$. The solid red curve lies beneath the black curve at layers 11 and 12. The gray horizontal lines mark the boundaries of the SBUV/2 layers (Table 1) labeled by the gray numbers on the right of each plot.

model forecast acts to keep the SD O-F below the SD O for all layers for the chemistry experiment, while the SD O-F of the experiment with no chemistry is greater than the SD O only at layer 12 . Like the equatorial region, the addition of chemistry lowers the value of SD O-F in the upper layers (10-12) due to a reduction of the standard deviation of the forecast model variance (SD F). In addition, the model with chemistry has somewhat smaller SD O-Fs in layers 7 and 8 due to higher covariances in those layers (not shown), suggesting that, in addition to reducing SD F, adding chemistry has improved the forecast to better match data variations.

Looking at the southern polar region in Fig. 12, it can be seen that without chemistry (Fig. 12a), passive advection forms ozone filaments with sharp gradients, such as the one near $240^{\circ} \mathrm{E}$ and $75^{\circ} \mathrm{S}$. With chemistry (Fig. 12b), the same filament is much broader, with much weaker gradients and a smaller dynamic range. The slightly smaller, time-averaged SD O-Fs with chemistry (Fig. 13) show that photochemical smoothing of filamentary structures such as these generally yields better fits to the observations in the southern polar region, even during this dynamically active time.
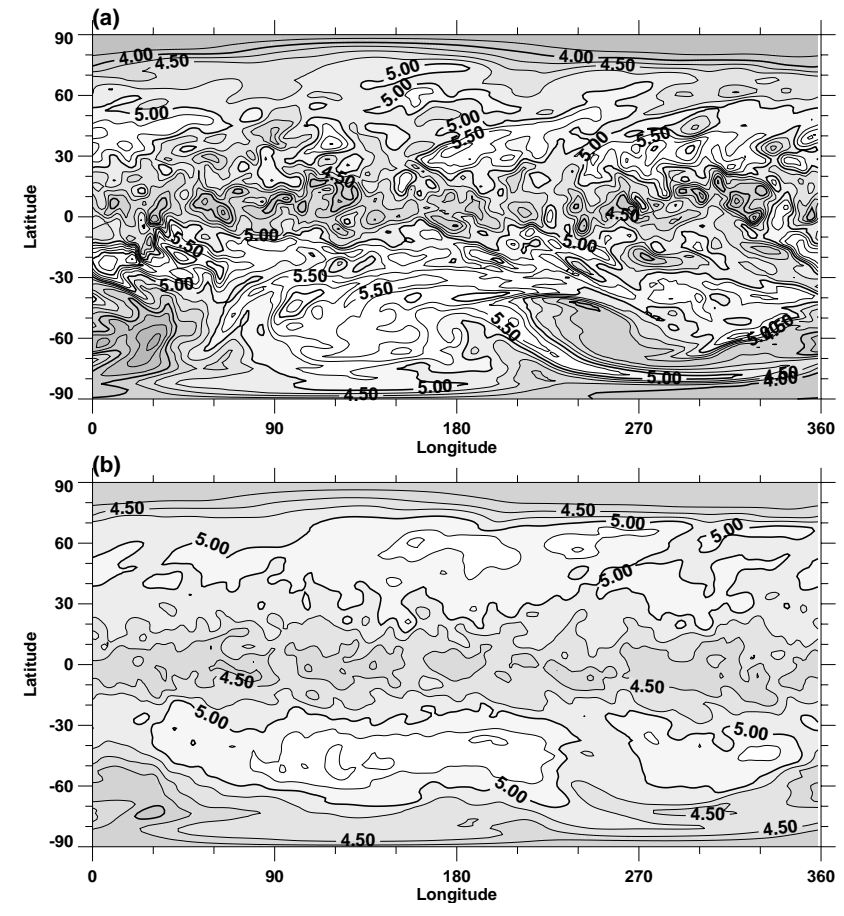

Fig. 12. Ozone (ppmv) at $1.65 \mathrm{hPa}$ taken from a 6 -h forecast valid on 24 September 2002 for GOATS experiments run (a) without and (b) with an ozone photochemistry parameterization. The contour interval is 0.25 pppmv. Darker contour curves are drawn at 4,5 , and 6 ppmv.

\subsection{Adaptive photochemistry}

Geer et al. (2007) used an ozone assimilation system to investigate how different ozone photochemistry schemes affected the quality of their ozone analyses. In some photochemistry schemes, they found systematic differences between the scheme's pre-specified zonal-mean reference states in Eq. (1) and those corresponding zonal means of the GCM forecasts and assimilated observations. These mismatches produced significant errors and biases in their final analyzed ozone fields. These problems originate from assimilating unbiased ozone observations using a biased ozone forecast model. In previous sections, we considered the opposite problem of assimilating biased observations using a largely unbiased ozone forecast model.

To remedy their problems, Geer et al. (2007) recommended that attention be paid in future work to making the reference states of the chemistry schemes more consistent with those of the GCM and assimilated observations, and specifically recommended that assimilation system use an ozone reference state $r_{o}$ based on the assimilated ozone data. This latter recommendation makes intuitive sense, as it forces the chemistry in Eq. (1) to linearize about reference states specified by the latest objectively analyzed observations, rather than about internal reference states that are 


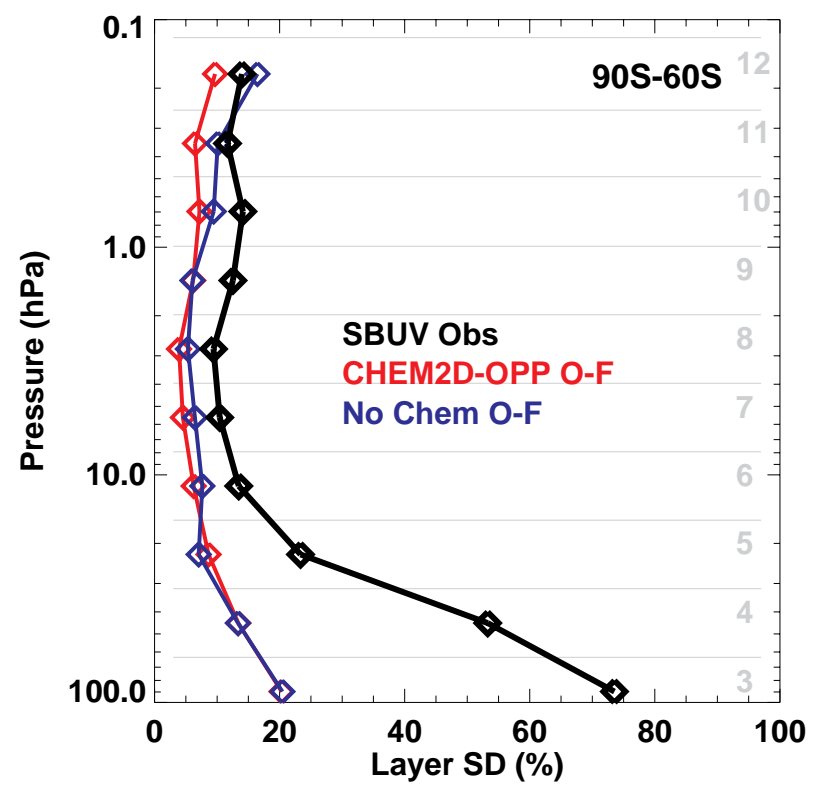

Fig. 13. Vertical profiles of the standard deviation of ozone O-Fs averaged over 10-30 September 2002 and from $90^{\circ} \mathrm{S}-60^{\circ} \mathrm{S}$ with (red curve) and without (blue curve) parameterized ozone photochemistry. Both curves are based on the unbiased SBUV/2 observations. The black curve plots the standard deviation of the SBUV/2 observations, $\left[\overline{O^{\prime 2}}\right]^{1 / 2}$. Note the change in $\mathrm{x}$-axis scale from Fig. 11. All curves are normalized by the layer values in Table 1. The gray horizontal lines mark the boundaries of the SBUV/2 layers (Table 1) labeled by the gray numbers on the right of each plot.

completely independent of (and possibly biased with respect to) those observations. Thus, in this section we use GOATS to test the Geer et al. (2007) recommendation by allowing the ozone and temperature reference states used by CHEM2DOPP in Eq. (1) to continually adjust to new values based on zonal-mean GOATS ozone and temperature fields at recently analyzed times. We refer to these GOATS experiments as runs using "adaptive" (as opposed to "standard" or "nonadaptive") ozone photochemistry.

Our initial implementation of this concept for testing in GOATS is as follows. At the start of each forecast, NOGAPS-ALPHA takes its initial state $(r, T)$, regrids it from model levels onto reference pressure levels, then computes their zonal means $r^{z m}$ and $T^{z m}$. Since a single $6 \mathrm{~h}$ analysis field can contain high-frequency variability, we average zonal mean estimates from a number of earlier GOATS analysis times using the following recursive time-averaging procedure, which blends the previous values of these reference states with these latest zonal means:

$r_{o}(\phi, p, t)=\left(\frac{J_{a v}-1}{J_{a v}}\right) r_{o}(\phi, p, t-\Delta t)+J_{a v}^{-1} r^{z m}(\phi, p, t)$
$T_{o}(\phi, p, t)=\left(\frac{J_{a v}-1}{J_{a v}}\right) T_{o}(\phi, p, t-\Delta t)+J_{a v}^{-1} T^{z m}(\phi, p, t)$

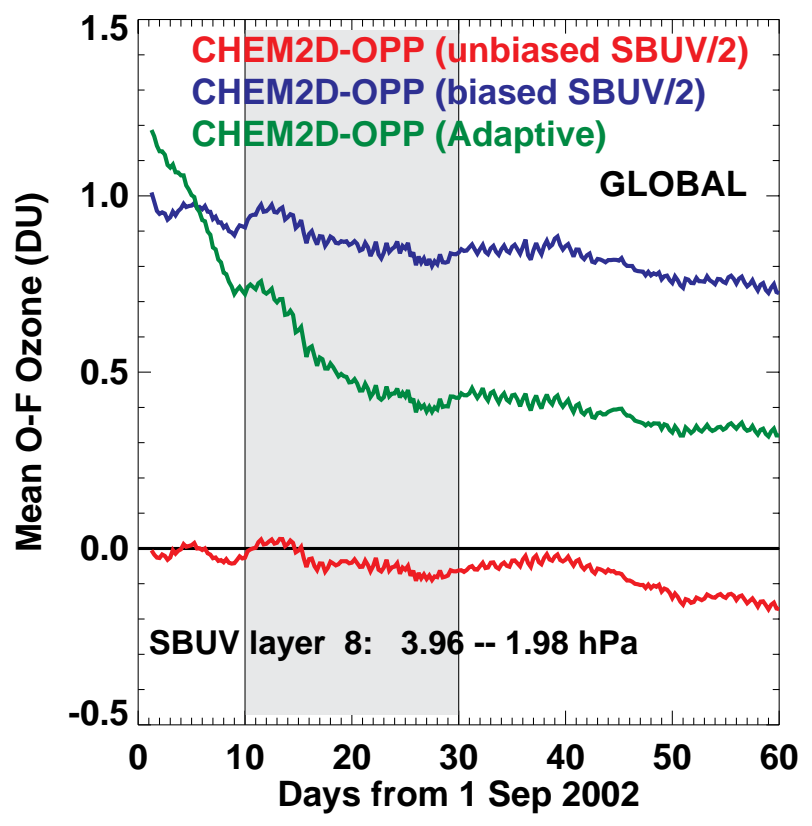

Fig. 14. Same as Fig. 7a with the addition of results taken from a GOATS run using CHEM2D-OPP modified to incorporate adaptive photochemical reference states for ozone and temperature (green curve).

Here $\phi$ is latitude, $p$ is pressure, $\Delta t=6 \mathrm{~h}, t$ is the current analysis time, and $J_{a v}$ can be viewed as (roughly) the number of $\Delta t=6 \mathrm{~h}$ analysis increments over which to apply the recursive average. For the runs here, we chose $J_{a v}=4$ $\left(J_{a v} \Delta t=24 \mathrm{~h}\right)$. For a cold start $(t=0)$, the initial condition we use at the first time step is $r_{o}=r^{z m}$ and $T_{o}=T^{z m}$.

Only the state from the previous $6 \mathrm{~h}$ analysis, $r_{o}(\phi, p, t-\Delta t)$, is read in and used by this averaging algorithm. While this greatly simplifies the implementation in NOGAPS-ALPHA, the drawback is that the time averaging window is a decaying exponential, rather than a sharp boxcar-like function between times $t-\left(J_{a v}-1\right) \Delta t$ and $t$. Nonetheless, the value of $J_{a v}$ does control the temporal decay rate of this exponential, and hence the width of the time averaging window. Since NOGAPS-ALPHA saves (and thus can restore) both the zonal mean and reference state fields from all the previous runs, much more sophisticated time averaging algorithms for these adaptive reference states could be devised and implemented. However, to demonstrate and test the concept in GOATS, we settled on the simplicity afforded by Eqs. (3) and (4).

Note that the photochemical reference states $r_{o}$ and $T_{o}$ are now time averages of output fields from the GOATS. Thus, the photochemistry is slaved to the GOATS output, and the two are now tightly coupled. With $r_{o}$ now set, $\Sigma_{o}$ is computed at each model time step by vertically integrating the $r_{o}$ profile at each location, and the pressure-gridded values of $\left(r_{o}, T_{o}, \Sigma_{o}\right)$ are interpolated at each model time step and location to the model's hybrid $\sigma-p$ vertical levels. 


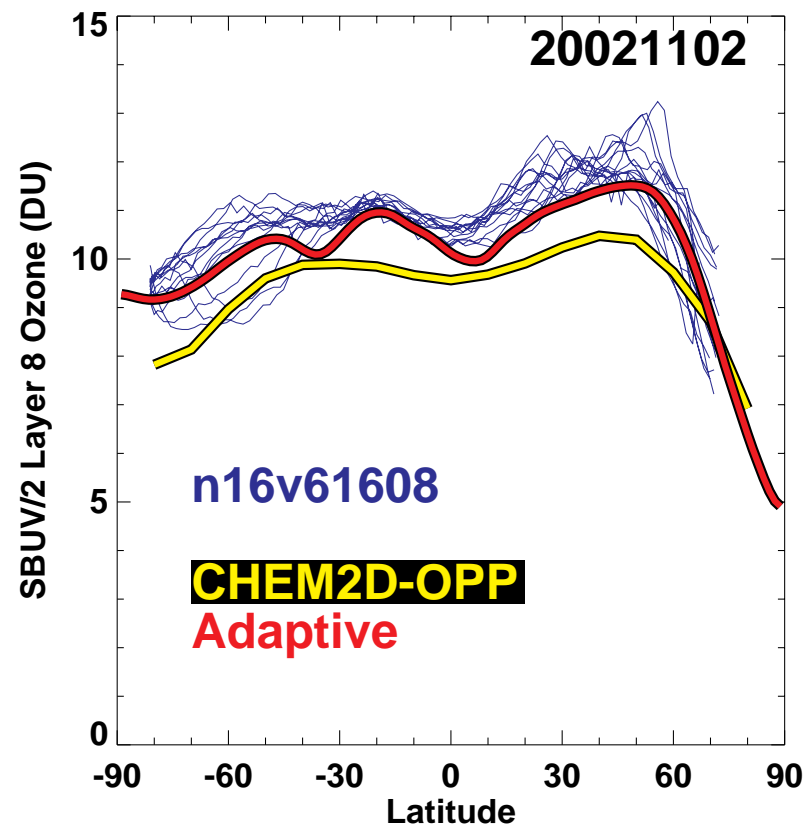

Fig. 15. SBUV/2 layer 8 ozone observations (DU) on 2 November 2002 plotted as a function of latitude for version n16v61608 (blue curves). Also plotted are the corresponding, verticallyintegrated over SBUV/2 layer 8, background ozone values, $r_{o}$, based on the Fortuin and Kelder (1998), zonal-mean ozone climatology (yellow curve), and the 2 November 2002 adaptive reference state (red curve) used to specify the CHEM2D-OPP relaxation term in Eq. (1).

Figure 14 shows the time series of the global averaged SBUV/2 layer 8 mean $\mathrm{O}-\mathrm{F}$ results as in Fig. 7a with the addition of the corresponding results from the experiment using the adaptive ozone and temperature photochemical reference states (3) and (4). This adaptive experiment was run with the high-biased SBUV/2 data, n16v61608. The change from the blue curve to the green curve shows the reduction in mean $\mathrm{O}-\mathrm{F}$ that occurs as the photochemistry adapts to the observations by adjusting the reference states. After two months of 6-hourly assimilation cycles, our test method of modifying the ozone and temperature climatology has not yet reduced the global mean $\mathrm{O}-\mathrm{F}$ 's to zero. However, the mean $\mathrm{O}-\mathrm{Fs}$ may still be decreasing slowly, and the value is less than half that of the biased data run without the adaptive algorithm.

Figure 15 shows how the adaptive ozone reference state (3) (red curve) has changed from the value it has in the nonadaptive case (yellow curve) by the end of the run ( 2 November 2002). The adaptive ozone reference state values are larger at all latitudes and better match the latitudinal structure of the observations (blue curves). The adaptive ozone reference state remains slightly smaller than the observations in agreement with the non-zero mean O-Fs seen in Fig. 14.

These results show that the adaptive ozone photochemistry, as initially implemented here, produces realistic ozone analyses in GOATS. Adaptive photochemistry reduces the mismatches between ozone observations and the photochemical reference states (Fig. 15), which in turn reduce mean O-Fs (Fig. 14). Thus, as suggested by Geer et al. (2007), when the original photochemical reference states are biased high or low, adaptive photochemistry should improve ozone analyses at higher altitudes when assimilating largely unbiased ozone (and temperature) data. However, our results reveal a disadvantage of adaptive photochemistry when assimilating biased ozone data. In this case, the adaptive photochemistry incorporates this observational bias into its reference states (Fig. 15), and hence into the ozone forecasts, so that the final ozone analysis fields retain some of the observational biases (Fig. 14). By contrast, earlier GOATS experiments that used an internal unbiased photochemical reference state were able to correct these observational biases during the forecast stage to yield a more unbiased ozone analysis (see Figs. 7, 8a and 14). Thus, systems continually assimilating ozone and temperature data that are prone to sudden offsets or slow drifts may be better off using nonadaptive photochemistry to maintain forecast reliability, and using mean $\mathrm{O}-\mathrm{Fs}$ to monitor the system for these input data biases as in Fig. 14. On the other hand, systems assimilating ozone and temperature data whose precision and accuracy are both high and stable may benefit by using adaptive photochemistry schemes. All these results reinforce the general point made by Geer et al. (2007) and others (e.g., Rood, 2005; Dee, 2005) that biases in either the ozone observations or the ozone forecast model can affect the performance of an ozone assimilation system.

\subsection{Dependence on upper boundary}

In this section we examine the dependence of the ozone assimilation on the upper boundary formulation. We present results in which the model forecast dynamics near the stratopause were degraded through changes in the initial meteorological fields used for the 6-h forecast.

As described in Sect. 2, in initializing the NOGAPSALPHA GCM for each 6-h forecast we used analyzed meteorological fields (from NAVDAS and GEOS4) up to a certain level, which were then progressively blended with climatology above. We ran the GOATS in two configurations: one with that transition at $0.2 \mathrm{hPa}$ (the highest pressure level available from the GEOS4 analysis) and a second with a degraded set of initial conditions, in which that transition altitude was lowered to $1 \mathrm{hPa}$. These two experiments also differed in the way the dynamical fields were initialized: for the $0.2 \mathrm{hPa}$ case the NOGAPS-ALPHA non-linear normal mode initialization (NNMI) scheme was used, while for the $1 \mathrm{hPa}$ case, the NNMI was deactivated. Thus, the run with the more realistic winds near the stratopause also benefited from a more dynamically balanced initial state produced by the NNMI. These initial conditions are used, not just at the start of the experiment, but at the start of every 6-h assimilation 

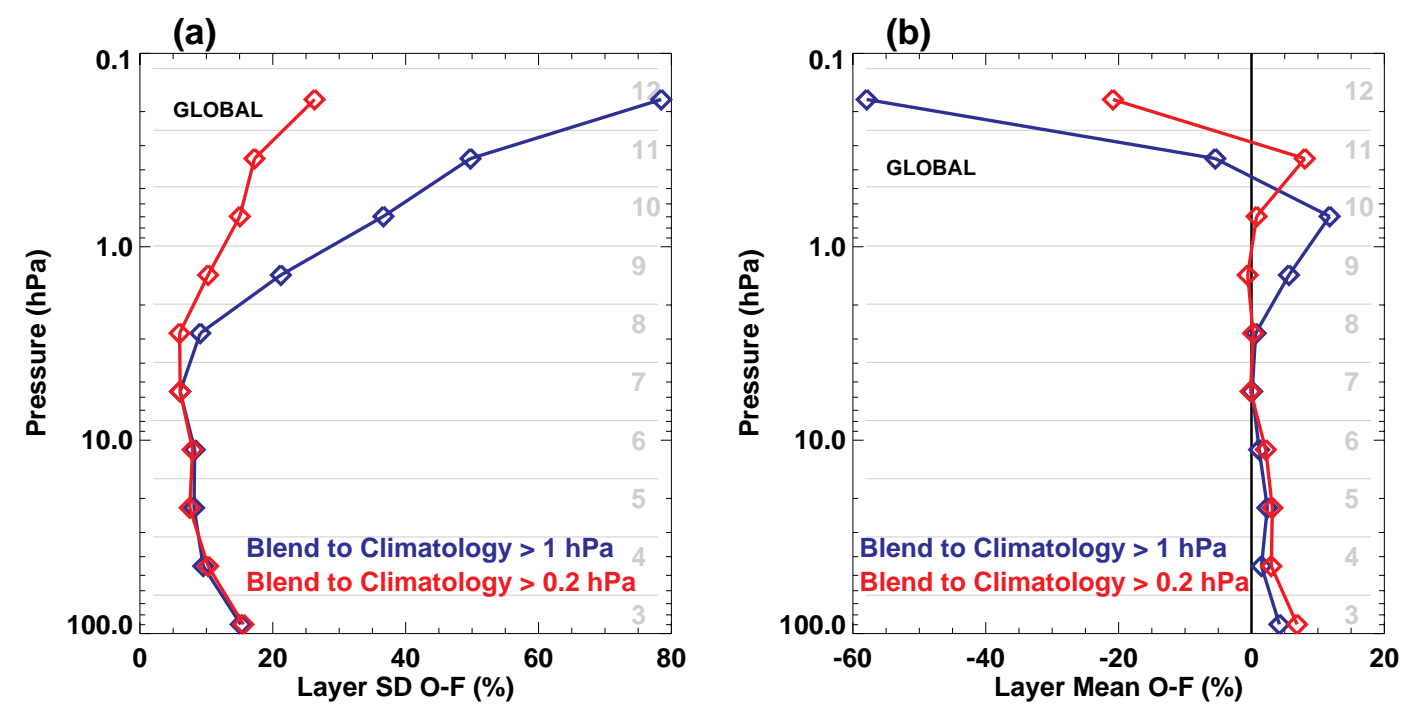

Fig. 16. Global (a) standard deviation and (b) mean ozone O-Fs averaged from 10-30 September 2002 normalized by the average SBUV/2 ozone for mid-September 2002 (Table 1) and expressed as a percent, plotted as a function of pressure. Both experiments are based on the unbiased SBUV/2 observations (n16v61814). The gray horizontal lines mark the boundaries of the SBUV/2 layers (Table 1) labeled by the gray numbers on the right of each plot.

cycle. Both of these experiments were run without chemistry to focus on changes to the dynamics.

Figure 16 shows the vertical structure of the O-Fs averaged from 10-30 September 2002. The mean O-F results for the $0.2 \mathrm{hPa}$ interface experiment (red curve, Fig. 16b) are from the same experiment as shown in Fig. 9b. Using a more realistic meteorological initialization field from 1$0.2 \mathrm{hPa}$ improves the global SD O-Fs at SBUV/2 layer 8 and above (Fig. 16a). At layer 12 the standard deviation is reduced from almost $80 \%$ to less than $30 \%$. Most of this reduction is due to the reduction in variance in the ozone forecast model, $\overline{F^{\prime 2}}$. While the most dramatic change brought about by the new initial conditions is in the standard deviation, the mean O-Fs (Fig. 16b) are also improved in levels 9,10 , and 12 . The mean $\mathrm{O}-\mathrm{F}$ is very small in level 8 and about 5\% larger in level 11, where the sign of the mean is changing with altitude. Thus, although the changes in initial meteorological conditions were at $1 \mathrm{hPa}$ and above, changes are seen down to $4 \mathrm{hPa}$ in the ozone $\mathrm{O}-\mathrm{Fs}$.

These results highlight the importance of developing accurate 3-D meteorological initial conditions to altitudes well above the altitude of interest for the ozone assimilation.

\section{Discussion}

The GOATS combines the GEOS ozone DAS, NOGAPS/NAVDAS meteorological analyses, and NOGAPSALPHA forecast model into a useful prototype system for testing several aspects of ozone data assimilation. Here we examined the effects of adding an ozone chemistry parameterization (both "standard" and "adaptive"), of observational data biases, and of improving the meteorological initialization at upper levels. Both mean and SD O-Fs were plotted as functions of time, SBUV/2 layers, and latitude regions, illustrating the dependence of the $\mathrm{O}-\mathrm{F}$ statistics on assimilation system changes.

Our "standard" ozone photochemistry parameterization was the linearized CHEM2D-OPP scheme in which the reference states $\left(r_{o}, T_{o}, \Sigma_{o}\right)$ were specified using long-term observational climatologies (see Fig. 3a). Results show that adding this parameterized ozone chemistry to the assimilation system can stabilize the ozone DAS at upper levels to drifts or biases in input data. The zonal mean assimilated ozone in GOATS runs with chemistry (Fig. 8a) remained relatively unchanged when fed with either the biased or unbiased set of SBUV/2 observations. This is because, in the ozone photochemistry parameterization, the second term on the righthand-side (RHS) of Eq. (1) is directly proportional to ozone, in contrast to the ozone advection term which is proportional only to ozone gradients. Thus, the ozone forecast model with chemistry is able to directly force mean ozone through the second term on the RHS of Eq. (1), whereas the advectiononly ozone forecast model can only produce mean ozone changes through eddy ozone fluxes or mean ozone gradients, neither of which depend on the overall mean ozone magnitude.

This difference between advective and photochemical tendencies can be especially dramatic when examining global mean quantities, where globally-averaged advection produces only a globally-averaged vertical eddy flux convergence tendency. Advection only runs can often produce relatively small global mean ozone tendencies (compared to the 
ozone tendencies provided by the observations) and therefore the global mean ozone produced by the ozone DAS under these conditions tends to draw strongly to the mean of the observations (Fig. 8b). The corresponding $\mathrm{O}-\mathrm{Fs}$ tend to be small in this case (Fig. 7b).

This leads to the general data assimilation question of how to interpret the mean $\mathrm{O}-\mathrm{Fs}$ of a state quantity (such as global averaged layer ozone) when that state quantity's model forecasted value is so tightly coupled to the observations (as in the global average of an advection-only ozone model) that the forecast is no longer providing an independent estimate of that quantity. Mean O-Fs that are independent of data biases (for example, Fig. 7b) are a symptom of a model forecasted value that is overly dependent on the observations. In this case, the model is no longer adding significant information about the value of that quantity to the data assimilation process, allowing that quantity's value to asymptote to the observations. In such a situation the mean $\mathrm{O}-\mathrm{Fs}$ can be very small because the assimilation system lacks independent model input on this quantity, however, these small mean $\mathrm{O}-\mathrm{Fs}$ can be misleading if this "null" model result is misinterpreted as a well-tuned predictive model result.

Adding physics (such as parameterized chemistry) that can directly affect the global average of a state quantity to a forecast model yields an independent estimate of this global averaged state quantity to the DAS. The global mean O-Fs will often increase (slightly for a well-tuned model, see Fig. 5b) over those generated by a "null" model, however, this increase (if not too large) is acceptable if the model with physics has improved the SD O-F significantly. In addition the model with physics is now contributing useful information to the DAS about these global mean quantities.

The situation is somewhat similar for the polar and equatorial mean $\mathrm{O}-\mathrm{Fs}$ in that without photochemistry the mean $\mathrm{O}-\mathrm{Fs}$ are nearly independent of the data bias (compare the blue curves in Figs. 9c and d; Figs. 10a and b; and Figs. 10c and d). The regional mean $\mathrm{O}-\mathrm{Fs}$ without photochemistry asymptote to the model's net advective flux convergence for the region. The ozone tendency from this regional net advective flux convergence balances the ozone tendency produced by the mean $\mathrm{O}-\mathrm{Fs}$. Note that the regional net advective flux convergence depends only on ozone gradients making it independent of mean biases. Thus, without chemistry regional mean $\mathrm{O}-\mathrm{Fs}$ will only be close to zero for regions when the net advective flux convergence is near zero. In the atmosphere these regional net advective flux convergences are often balanced by photochemistry, and in an ozone DAS with photochemistry the regional mean $\mathrm{O}-\mathrm{Fs}$ can be near zero without requiring the regional net advective flux convergence to be near zero (for example, Fig. 10d, in layers 8-10).

The mean $\mathrm{O}-\mathrm{F}$ results reported here also give guidance to the monitoring of an ozone assimilation system. Without a chemistry constraint, gradual changes in observation biases cannot be detected in the global mean ozone O-Fs (Fig. 7b) or regional mean ozone O-Fs (Figs. 9 and 10) and these biases will be incorporated into the final ozone analysis (Fig. 8b). Using "standard" linearized photochemistry, ozone at the levels where photochemistry is important can show the development of ozone observation biases in the global mean $\mathrm{O}-\mathrm{F}$ (Fig. 7a) while at the same time maintaining more stable well-performed ozone analysis fields (Fig. 8a). Experiments with a preliminary "adaptive" linearized photochemistry fall between these two limits (Fig. 14), showing some chemical change but building observational bias into the photochemical reference state (Fig. 15) and thus into the ozone analysis fields.

Of course, with or without chemistry the ozone DAS will show a jump in mean $\mathrm{O}-\mathrm{Fs}$ if the input observations change suddenly (e.g., a step function jump with chemistry; a spike followed by an exponential decay without chemistry). This agrees with the global mean $\mathrm{O}-\mathrm{F}$ time series shown in Stajner et al. (2004) for SBUV/2 layer 5, where a spike followed by a decay occurred coincident with a SBUV/2 instrument calibration change. In Stajner et al. (2004) both the experiments with and without chemistry showed a spike followed by a decay, presumably because the chemistry parameterization used does not play a large role in layer $5(\sim 32-$ $16 \mathrm{hPa}$ ), where photochemical timescales are long (see, e.g., Fig. 3b). While the best way to monitor input data biases is to look at off-line observation minus climatology statistics (like the yellow curves in Figs. 9 and 10), when the climatological statistic can be built into the assimilation cycle through the standard chemistry parameterization's reference state, the assimilation's operationally generated $\mathrm{O}-\mathrm{Fs}$ can provide a convenient and reliable monitoring proxy at levels where photochemical time scales are short (the red curves in Figs. 9 and 10).

Our GOATS simulations have highlighted how the CHEM2D-OPP standard photochemistry parameterization in Eq. (1) yields an ozone assimilation that is more robust to any sudden anomalies, drifts or biases in the input observations (see, e.g., Fig. 8). This useful property of the parameterized chemistry in our GOATS runs was aided by using a reference ozone state $r_{0}$ (Fig. 3a) that was based on long-term SBUV ozone measurements (Fortuin and Kelder, 1998), and thus provided a reliable measure of typical SBUV ozone values anticipated within each layer (see Fig. 6). Thus, in addition to using a chemistry scheme like CHEM2D-OPP with reliable photochemical inputs, our work has shown that the choice of its reference state climatologies $r_{0}$ and $T_{0}$ is also important. Ideally, the ozone reference state $r_{0}$ should be a longterm observational mean of all the different types of ozone observations currently entering the assimilation, so that it incorporates to some extent the typical vertical and horizontal resolution of the input ozone observations. For example, if future GOATS experiments were to assimilate higher vertical-resolution ozone limb data such as from HALOE, MLS, or MIPAS (e.g., Wargan et al., 2005), the GOATS assimilation of these data would likely work better by replacing the SBUV-based reference state used here with a new 
reference climatology $r_{o}$ based on long-term data from these instruments (e.g., Grooss and Russell, 2005).

We have also used the GOATS to test the ability of "adaptive" linearized ozone photochemistry, in which $r_{o}$ and $T_{o}$ adapt over time to reflect zonal means of ozone and temperature from GOATS runs at recent times, to reduce biases in the mean ozone O-Fs. Results show a significant reduction in the global mean O-Fs (Fig. 14) and a stable ozone reference state closer to the observations (Fig. 15). Thus, the use of adaptive photochemistry climatologies is a viable option for improving the mean assimilation at the expense of increased sensitivity of the ozone assimilation to data drift coupled with decreased sensitivity of the mean $\mathrm{O}-\mathrm{Fs}$ to data drift. An adaptive formulation may be particularly useful when assimilating new instrument observations with high precession and accuracy, minimal drifts, and for which a long-term climatology has yet to be formulated. The ozone assimilation with adaptive photochemistry will then reflect the instrument biases, if any.

A possible problem with the adaptive formulation is that the photochemistry climatologies will depend on the both the forecast model dynamics and the observations. In Fig. 15 there is an increase in latitudinal structure of the adaptive ozone reference state compared with the non-adaptive reference state and the observations, that is likely a consequence of the model dynamics. In the example in Fig. 15, the additional latitudinal structure in the adaptive ozone reference state is not large enough to be a problem and the adaptive ozone reference state at all other levels was found to be stable (not shown). However, at upper levels especially, the model's artificial upper boundary condition may create an unstable or unrealistic climatology, especially if the data uncertainty is large in those regions.

The SD O-Fs with and without chemistry show that chemistry can improve the ozone forecast model in two ways:

1. by substantially reducing the ozone forecast variance in models where the ozone forecast variance is likely too high (Figs. 11 and 13)

2. by increasing the covariance between the ozone forecast and the observations (Table 2).

The high variance in ozone seen without chemistry is due to vertical advection by resolved gravity waves (see Fig. 12a, especially in the tropics) and horizontal advection by planetary-scale waves (seen in the southern polar region in Fig. 12a). Chemistry in the upper stratosphere reduces these advectively created gradients via photochemical relaxation, producing better agreement with the observations. For monitoring and analysis it may be useful to plot or state the value of the observation standard deviation as a sensible upper limit to the desirable SD O-F. If the SD O-F is greater than the SD O, then the ozone DAS can probably be improved (at least in the upper stratosphere) with more forecast model diffusion to damp spurious small-scale dynamics (see below).

GOATS runs were also used to investigate the role of upper-level meteorological initialization on ozone assimilation. Since GOATS re-initializes every $6 \mathrm{~h}$, blending the operational NOGAPS/NAVDAS and GEOS4 upper-level meteorological analyses with wind and temperature climatologies above, the potential for dynamical imbalances and poor or excessively noisy model transport exists. Such problems are ameliorated by making the transition to climatology as high as possible and performing nonlinear normal mode initialization to enforce dynamical balance and minimize spurious generation of gravity waves which add "noise" to the forecast (Fig. 16). However, there is some evidence that the dynamical adjustment to the upper level wind and temperature climatologies may still be degrading the GOATS results at the upper levels. For example, the large SD O-Fs are seen at upper levels when GOATS is run without chemistry (Figs. 11 and 13), as well as the somewhat anomalous mean O-Fs found in layer 12 (Figs. 9 and 10). Diurnal photochemistry, which CHEM2D-OPP does not currently contain, may also affect layer 12 .

\section{Conclusions}

GOATS has provided an opportunity to study the basic features of ozone data assimilation and the properties of the $\mathrm{O}-\mathrm{Fs}$ it generates. We plan to use this experience with GOATS as guidance in developing ozone data assimilation in a NOGAPS-ALPHA/NAVDAS environment. The $\mathrm{O}-\mathrm{F}$ residuals, while providing convenient and very useful information, need to be considered as a part of a more comprehensive evaluation of an assimilation system and its components based on comparisons with high quality independent observations. While GOATS is concerned with ozone assimilation and photochemistry, the results presented here apply quite generally to any constituent assimilation in which chemistry or microphysics is added to an advection model.

In summary:

1. Zonal mean ozone analyses are more independent of observation biases and drifts when using an ozone photochemistry parameterization (OPP) at altitudes above the middle stratosphere where the ozone photochemical relaxation rates become fast.

2. Mean ozone $\mathrm{O}-\mathrm{Fs}$ are more sensitive to observation drifts when using an OPP at altitudes above the middle stratosphere where the ozone photochemical relaxation rates become fast.

3. Ozone SD O-Fs are reduced in the upper stratosphere when using an OPP due to a reduction of forecast model noise and to increased covariance between the forecast model and observations. 
4. Changing the OPP reference state to match the observations by using an "adaptive" OPP scheme reduces the mean ozone $\mathrm{O}-\mathrm{Fs}$ at the expense of zonal mean ozone analyses being more susceptible to data biases and drifts.

5. The upper boundary of the ozone DAS can affect the quality of the ozone analysis and therefore should be placed well above (at least a scale height) the region of interest.

Acknowledgements. This research was supported by the Office of Naval Research through NRL's base 6.2 program, the National Polar-orbiting Operational Environmental Satellite System Integrated Program Office, and the Joint Center for Satellite Data Assimilation. This work was also supported in part by a grant of computer time from the DoD High Performance Computing Modernization Program at the U.S. Army Space and Missile Defense Command Simulation Center. The SBUV/2 observations were obtained from NOAA/NESDIS with support from the NOAA Climate and Global Change Program Atmospheric Chemistry Element.

Edited by: W. T. Sturges

\section{References}

Allen, D. R., Coy, L., Eckermann, S. D., McCormack, J. P., Manney, G. L., Hogan, T. F., and Kim, Y.-J.: NOGAPS-ALPHA simulations of the 2002 Southern Hemisphere stratospheric major warming, Mon. Wea. Rev., 134, 498-518, 2006.

Bhartia, P. K., McPeters, R. D., Mateer, C. L., Flynn, L. E., and Wellemeyer, C.: Algorithm for the estimation of vertical ozone profiles from the backscattered ultraviolet technique, J. Geophys. Res., 101, 18 793-18 806, 1996.

Bloom, S., da Silva, A., Dee, D., Bosilovich, M., Chern, J.-D., Pawson, S., Schubert, S., Sienkiewicz, M., Stajner, I., Tan, W.W., and Wu, M.-L.: Documentation and validation of the Goddard Earth Observing System (GEOS) data assimilation system - version 4, NASA Tech. Mem. NASA/TM-2005-104606, 15, Technical Report Series on Global Modeling and Data Assimilation, edited by: Suarez, M. J., 165 pp., available online at http://ntrs.nasa.gov, 2005

Cariolle, D. and Déqué, M.: Southern hemisphere medium-scale waves and total ozone disturbances in a spectral general circulation model, J. Geophys. Res., 91, 10 825-10 846, 1986.

Cohn, S. E., da Silva, A., Guao, J., Sienkiewicz, M., and Lamich, D.: Assessing the effects of data selection with the DAO physical-space statistical analysis system, Mon. Wea. Rev., 126, 2913-2926, 1998.

Daley, R. and Barker, E.: NAVDAS: formulation and diagnostics, Mon. Wea. Rev., 129, 869-883, 2001

Dee, D. P.: Bias and data assimilation, Quart. J. Roy. Meteorol. Soc., 131, 3323-3343, 2005.

Derber, J. C. and Wu, W. S.: The use of TOVS cloud-cleared radiances in the NCEP SSI analysis system, Mon. Wea. Rev., 126, 2287-2299, 1998.
Dethof, A. and Holm, E. V.: Ozone assimilation in the ERA-40 reanalysis project, Quart. J. Roy. Meteorol. Soc., 130, 2851-2872, 2004.

Eckermann, S. D., McCormack, J. P., Coy, L., Allen, D., Hogan, T., and Kim, Y.-J.: NOGAPS-ALPHA: A prototype high-altitude global NWP model, Preprint Vol. Symposium on the 50th. Anniversary of Operational Numerical Weather Prediction, American Meteorological Society, University of Maryland, College Park, MD, 14-17 June, Paper P2.6, 23 pp, available online at http://uap-www.nrl.navy.mil/dynamics/ papers/Eckermann_P2.6-reprint.pdf, 2004.

Eckermann, S. D., Wu, D. L., Doyle, J. D., Burris, J. F., McGee, T. J., Hostetler, C. A., Coy, L., Lawrence, B. N., Stephens, A., McCormack, J. P., and Hogan, T. F.: Imaging gravity waves in lower stratospheric AMSU-A radiances, Part 2: Validation case study, Atmos. Chem. Phys., 6, 3343-3362, 2006, http://www.atmos-chem-phys.net/6/3343/2006/.

Fleming, E. L., Chandra, S., Barnett, J. J., and Corney, M.: Zonal mean temperature, pressure, zonal wind, and geopotential height as functions of latitude, COSPAR International Reference Atmosphere: 1986, Part II: middle atmosphere models, Adv. Space Res., 10(12), 11-59, 1990.

Fortuin, J. P. F. and Kelder, H.: An ozone climatology based on ozonesonde and satellite measurements, J. Geophys. Res., 103, 31 709-31 734, 1998.

Geer, A. J., Peubey, C., Bannister, R. N., Brugge, R., Jackson, D. R., Lahoz, W. A., Migliorini, S., O'Neill, A., and Swinbank, R.: Assimilation of stratospheric ozone from MIPAS into a global general-circulation model: The September 2002 vortex split, Quart. J. Roy. Meteorol. Soc., 132, 231-257, 2006.

Geer, A. J., Lahoz, W. A., Jackson, D. R., Cariolle, D., and McCormack, J. P.: Evaluation of linear ozone photochemistry parameterizations in a stratosphere-troposphere data assimilation system, Atmos. Chem. Phys., 7, 939-959, 2007, http://www.atmos-chem-phys.net/7/939/2007/.

Grooss, J.-U. and Russell III, J. M.: Technical note: a stratospheric climatology for $\mathrm{O}_{3}, \mathrm{H}_{2} \mathrm{O}, \mathrm{CH}_{4}, \mathrm{NO}_{\mathrm{x}}, \mathrm{HCl}$ and $\mathrm{HF}$ derived from HALOE measurements, Atmos. Chem. Phys., 5, 2797-2807, 2005, http://www.atmos-chem-phys.net/5/2797/2005/.

Hogan, T. F. and Rosmond, T.: The description of the Navy Operational Global Atmospheric Prediction System's spectral forecast model, Mon. Wea. Rev., 119, 1786-1815, 1991.

Jang, K.-I., Zou, X., DePondeca, M. S. F. V., Shapiro, M., Davis, C., and Krueger, A.: Incorporating TOMS ozone measurements into the prediction of the Washington, D.C., winter storm during 24-25 January 2000, J. Appl. Meteorol., 42, 797-812, 2003.

John, V. O. and Buehler, S. A.: The impact of ozone lines on AMSU-B radiances, Geophys. Res. Lett., 31, L21108, doi:10.1029/2004GL021214, 2004.

Kondragunta, S., Flynn, L. E., Neuendorffer, A., Miller, A. J., Long, C., Nagatani, R., Zbou, S., Beck, T., Beach, E., McPeters, R, Stolarski, R., Bhartia, P. K., DeLand M. T., and Huang, L.-K.: Vertical structure of the anomalous 2002 Antarctic ozone hole, J. Atmos. Sci., 62, 801-811, 2005.

Long, C. S., Miller, A. J., Lee, H. T., Wild, J. D., Przywarty, R. C., and Hufford, D.: Ultraviolet index forecasts issued by the National Weather Service, Bull. Amer. Meteorol. Soc., 77, 729748,1996 
McCormack, J. P. and Siskind, D. E.: Simulation of the quasibiennial oscillation and its effect on stratospheric $\mathrm{H}_{2} \mathrm{O}, \mathrm{CH}_{4}$, and age of air with an interactive two-dimensional model, J. Geophys. Res., 107(D22), 4625, doi:10.1029/2002JD002141, 2002.

McCormack, J. P., Eckermann, S. D., Coy, L. Allen, D. R., Kim, Y.J., Hogan, T., Lawrence, B. N., Stephens, A., Browell, E. V., Burris, J., McGee, T., and Trepte, C. R.: NOGAPS-ALPHA model simulations of stratospheric ozone during the SOLVE2 campaign, Atmos. Chem. Phys., 4, 2401-2423, 2004, http://www.atmos-chem-phys.net/4/2401/2004/.

McCormack, J. P., Eckermann, S. D., Siskind, D. E., and McGee, T.: CHEM2D-OPP: a new linearized gas-phase ozone photochemistry parameterization for high-altitude NWP and climate models, Atmos. Chem. Phys., 6, 4943-4972. 2006.

Oikonomou, E. K. and O'Neill, A.: Evaluation of ozone and water vapor fields from the ECMWF reanalysis ERA40 during 1991-1999 in comparison with UARS satellite and MOZAIC aircraft observations, J. Geophys. Res., 111, D14109, doi:10.1029/2004JD005341, 2006.

Newman, P. A. and Nash, E. R.: The unusual southern hemisphere stratosphere winter of 2002, J. Atmos. Sci., 62, 614-628, 2005.

Peuch, A., Thepaut, J. N., and Pailleux, J.: Dynamical impact of total-ozone observations in a four-dimensional variational assimilation, Quart. J. Roy. Meteorol. Soc., 126, 1641-1659, 2000.

Polavarapu, S., Shepherd, T. S., Rochon, Y., and Ren, S.: Some challenges of middle atmosphere data assimilation, Quart. J. Roy. Meteorol. Soc., 131, 3513-3527, 2005.

Riishojgaard, L. P., Stajner, I., and Lou, G.-P.: The GEOS ozone data assimilation system, Adv. Space Res., 25, 1063-1072, 2000.
Rood, R.: Assimilation of stratospheric meteorological and constituent observations: A review, SPARC Newsletter, 25, 3137, available online at http://www.atmosp.physics.utoronto.ca/ SPARC/Newsletter25.pdf, 2005

Stajner, I., Riishojgaard, L. P., and Rood, R. B.: The GEOS ozone data assimilation system: Specification of error statistics, Quart. J. Roy. Meteorol. Soc., 127, 1069-1094, 2001.

Stajner, I. and Wargan, K., Antarctic stratospheric ozone from the assimilation of occultation data, Geophys. Res. Lett., 31, L18108, doi:10.1029/2004GL020846, 2004.

Stajner, I., Winslow, N., Rood, R. B., and Pawson, S.: Monitoring of observation errors in the assimilation of satellite ozone data, J. Geophys. .Res., 109, D06309, doi:10.1029/2003JD004118, 2004.

Stajner, I., Wargan, K., Chang, L. P., Hayashi, H., Pawson, S., and Nakajima, H.: Assimilation of ozone profiles from the Improved Limb Atmospheric Spectrometer-II: Study of Antarctic Ozone, J. Geophys. Res., 111, D11S14, doi:10.1029/2005JD006448, 2006.

Swinbank, R. and Ortland, D. A.: Compilation of wind data for the Upper Atmosphere Research Satellite (UARS) Reference Atmosphere Project, J. Geophys. Res., 108(D19), 4615, doi:10.1029/2002JD003135, 2003.

Wargan, K., Stajner, I., Pawson, S., Rood, R. B., and Tan, W.W.: Assimilation of ozone data from the Michelson Interferometer for Passive Atmospheric Sounding, Quart. J. Roy. Meteorol. Soc., 131, 2713-2734, 2005. 